\title{
Refugees without Assistance: English-Language Attainment and Economic Outcomes in the Early Twentieth Century
}

October 7, 2022

$\begin{array}{ccccc}\text { Ran Abramitzky } & \text { Leah Boustan } & \text { Peter Catron } & \text { Dylan Connor } & \text { Rob Voigt } \\ \text { Stanford \& NBER } & \text { Princeton \& NBER } & \text { U Washington } & \text { Arizona State } & \text { Northwestern }\end{array}$

\begin{abstract}
The United States has admitted more than 3 million refugees since 1980 through official refugee resettlement programs. Scholars attribute the success of refugee groups to governmental programs on assimilation and integration. Before 1948, however, refugees arrived without formal selection processes or federal support. We examine the integration of historical refugees using a large archive of recorded oral history interviews to understand linguistic attainment and economic outcomes of migrants who arrived in the early twentieth century. Using fine-grained measures of vocabulary, syntax and accented speech, we find that refugee migrants achieved a greater depth of English vocabulary than did economic migrants, a finding that holds even when comparing migrants from the same country of origin or religious group. This study improves on previous research on immigrant language acquisition and refugee incorporation, which typically rely on self-reported measures of fluency and assign refugee status based on country-of-birth alone. Our findings are consistent with the hypothesis that refugees had greater exposure to English or more incentive to learn, due to the conditions of their arrival and their inability to immediately return to their origin country. These patterns provide an optimistic historical precedent for the incorporation of refugees into American society.
\end{abstract}

Acknowledgements: We acknowledge the excellent research assistance of Victoria Angelova, Harriet Brookes Gray, Sarah Frick and Myera Rashid. Sima Biondi, Alicia Liu, Lori Mitrano, Lorenzo Rosas, Antigone Xenopoulos and Adam Zhang helped to collect variables from the oral history interviews. Jared Grogan, Bailey Palmer and James Reeves coded the interviews for accented speech. Tom Zohar oversaw audio transcription of missing transcripts. We appreciate suggestions from audiences at Universitat Automoma de Barcelona, UC-Berkeley, European Social Science History Association, Harvard, University of Nottingham, Pompeu Fabra, University of Chicago, and University College, London. 
From its founding, the United States has been an immigrant-receiving nation. More than one hundred million immigrants have settled in the US since 1850, and their settlement has (re)shaped US society. In recent decades, 15-20 percent of immigrants have arrived as refugees or asylum seekers in response to persecution or violence in their home countries (U.S. Department of Homeland Security 2016). Before the establishment of the modern refugee admission system in 1980, many immigrants moved to the US for similar reasons, but were not officially labeled as 'refugees' (Arar and FitzGerald 2022).

Contemporary research finds that, in many destination countries, refugees face disadvantages relative to other immigrants when they first arrive in a new country (the "refugee gap") but are able to overcome these disparities over time through successful integration into the mainstream (Akresh 2008; De Vroome and Van Tubergen 2010; Connor 2010; Aydemir 2011; Cortes, 2004; Chin and Cortes, 2015; Bakker, Dagevos, and Engbersen 2017; Evans and Fitzgerald 2017; Ruiz and Vargas-Silva 2018; Zwysen 2019; Fasani, Frattini, and Minale 2020).

Some scholars suggest that the integration of refugee populations is facilitated by access to resettlement programs and governmental assistance, and by the benefits associated with legal permanent residence and eventual citizenship (Bloemraad 2006; Jiménez 2011; Waters and Pineau 2015). This research often assumes that, absent this assistance, refugees would not integrate as rapidly. By contrast, other scholars emphasize that integration of refugees may differ from economic migrants even without governmental support due to fundamental aspects of the refugee experience - namely, the conditions of refugee arrivals and their inability to engage in imminent return (Friedberg, 2000; De Vroome and van Tubergen 2010; van Tubergen 2010; Dustmann and Gorlach 2016; Becker et al. 2020; Adda, et al. 2020). Because of their different migration motives and integration strategies, refugees may be more likely than economic migrants to be exposed to the native-born in neighborhoods, workplaces and other points of contact, or to make local investments in human and social capital (Jasso and Rosenzweig 1990).

This paper explores the process of refugee integration in a period - the early twentieth century United States - when refugees did not receive governmental support, nor did they enjoy an advantage in access to legal permanent residency or citizenship (Abramitzky and Boustan, 2017). Furthermore, governmental resettlement assistance was nonexistent, and what help there was came from ethnic or religious volunteers, who provided low levels of aid that was not tied to refugee status (Holman, 1996; Abramitzky, Boustan and Connor, 2020). Instead, this private aid 
generally tied to class status, allowing poor and working class economic migrants and refugees to benefit equally. Thus, this historical setting - a period without governmental assistance - allows us to shed light on fundamental aspects of the refugee experience in shaping the refugee integration process.

Specifically, we compare the English language attainment of refugees to other immigrants in the United States in the early twentieth century. Despite being a multilingual nation, English is by far the dominant language in the US, and learning English provides important advantages for immigrant incorporation. We adapt measures of language attainment derived from the field of linguistics to measure both complexity of speech (in vocabulary and sentence structure) and fluency (in accentedness and speech rate). We use a new dataset of 1,200 oral history transcripts and audio files of immigrants who arrived in the US through Ellis Island in the early twentieth century; overall, the transcripts of these interviews comprise more than 1.2 million words. Moreover, with the exception of accent, which we measure with subjective human ratings, we use computational methods to automatically extract these linguistic measures from oral history transcripts. Our approach adds to recent computational analyses used in the subfield of international migration, which have primarily focused on online digital trace data (e.g., Zagheni et al. 2017; Florès 2017; Spörlein and Schlueter 2021), opening possibilities for further work in this area at very large scales.

We find that immigrants who reported leaving Europe in response to war, violence or persecution ("refugee migrants") achieved a greater depth of English vocabulary than immigrants who came to join family or find better job opportunities ("economic migrants"), despite the lack of governmental support at the time. ${ }^{1}$ We find that this refugee advantage holds even after controlling for country of origin, religion and decade of arrival. (By contrast, much of the modern scholarship defines refugee status on the basis of country of origin; see Chin and Cortes, 2015). The refugee advantage is also present after controlling for father's occupation and urban status during childhood to address concerns that refugee migrants may have come from higher than average socioeconomic backgrounds. Jewish immigrants are over-represented in our refugee subsample, but the pattern of English attainment is, if anything, stronger in the non-Jewish

\footnotetext{
${ }^{1}$ Throughout the paper, we use the term "economic migrants" to refer to immigrants who report coming to the US for reasons other than persecution or violence. The majority of this group (85 percent) report immigrating either to find economic opportunity or to follow family members.
} 
immigrant population. We document that all three aspects of linguistic proficiency - vocabulary, syntax and accentedness - are correlated with earnings in mid-career, although we note that the temporal ordering of this outcomes (income measured circa age 40 and English proficiency at the end of life) makes it hard to assign a causal direction to this relationship.

Our results derive from a new dataset of oral history transcripts and recordings, each roughly an hour in length. The interviews were conducted in the 1970s and 1980s in English, for a sample of immigrants who arrived in the US between 1893 and 1957. The sample was originally assembled by the Statue of Liberty - Ellis Island Foundation (SOLEIF). Oral histories provide a few unique advantages for understanding immigrant integration. First, they allow us to use actual immigrant speech derived from transcripts and audio files to construct more objective and detailed measures of English attainment taken from the field of linguistics, rather than the coarse measures of English fluency available on surveys. Prior work on linguistic attainment, both in the past and today, is based on self-assessed scales (e.g., answering that one speaks English "very well") from the census or other sources (Portes and Hao 1998; Espenshade and Fu 1997; Waters and Pineau 2016; Fischer and Hout 2006). Second, oral histories retrospectively capture aspects of an immigrant's socio-economic context before migration that usually remain unobserved, including religion, urban status in childhood, and father's occupation in the home country. Third, oral histories provide details on stated reason for migration, allowing us to classify migrants into refugees and economic migrants based on self-perception rather than relying on proxies for refugee status like nationality and year of arrival (Donato and Ferris 2020). ${ }^{2}$ Importantly, in our context, immigrants from the same country of origin, arrival period and religious group report different reasons for migration, allowing us to make comparisons within rather than across groups. We also leverage genealogical methods to link immigrants in our interview sample to the 1940 population

\footnotetext{
${ }^{2}$ Garip (2016) provides another example of creating a typology of immigrants using information from qualitative interviews and survey data. FitzGerald and Arar (2018) have emphasized that the lack of information on refugee status in standard datasets has "analytically hobbled" research on refugee populations. There are two small-scale surveys that identify modern refugees in the US the New Immigrant Survey, used in this article below, which was discontinued in the second wave due to lack of funding, and the Annual Survey of Refugees by which only one year, 2016, is available to researchers (see Chin and Cortes 2015; Akresh 2008; Tran and Lara-Garcia 2020). Other data sets that separate refugees from non-refugees are completely unavailable to researchers (Bevelander 2016).
} 
census, using first and last name and other identifying information, in order to extract measures of income, occupation, and geographic location from the census at mid-life.

Arar and FitzGerald (2022) argue that migration occurs on a "continuum of compulsion and freedom." On one end of the spectrum are immigrants who move to improve their quality of life, and on the other are immigrants escaping life and death circumstances. Classifying immigrants on a binary as economic migrants or refugees can often miss the gradations of compulsion that underlie the decision to leave home. We use double coding of each oral history to overcome this limitation, defining immigrants who are classified as refugees by both rounds of coders as "refugees" and immigrants who are classified as refugees by only one round of coders as "mixed reason" (persecution-economic) movers. The most common reasons for classification as a "mixed reason" mover are stage migration (an immigrant who flees imminent danger for a third country before moving to the US) or family migration (an immigrant who hastens to join earlier economic migrants due to unexpected conflict).

We end the paper with a comparison of our historical findings to the best available source of modern data on the refugee population - the New Immigrant Survey (NIS). Unlike the refugees in our historical dataset, modern refugees enjoy both legal status and government relocation supports, allowing us to compare the attainment of English proficiency across two legal regimes. We find a similar pattern in the modern data, whereby refugees are more likely than other legal permanent residents to report speaking some English. Access to language classes is one of the most common forms of refugee assistance today. Notably, we find that refugees enjoy greater language ability today even after controlling for taking a recent English class or an English class before arrival. Both in the past and today, we find evidence that refugees achieve more complete linguistic assimilation even without governmental supports.

\section{Background and conceptual framework: Refugee integration and linguistic attainment Refugee integration}

The integration of refugees has been of considerable interest in recent years with worldwide flows from Syria, Afghanistan, and Ukraine among other conflict zones. One hundred million people have been forcibly displaced from their homes due to ongoing conflicts throughout the world (UNHCR 2022). Although many refugees today remain internally displaced or live in refugee camps, some are resettled in other countries. 
Scholars argue that resettled refugees integrate more quickly than non-refugee migrants because they benefit from programs in the United States and elsewhere that act as effective integration policies (Bloemraad 2006; Jiménez 2011; Waters and Pineau 2015; Zolberg 1988; Menjivar 2000; Tran and Lara-Garcia 2020). Both the segmented assimilation and neoassimilation approaches emphasize that refugees benefit from favored treatment in formal institutions and law, including government resettlement assistance and access to legal permanent residence (Portes and Rumbaut 2001; Alba and Nee 2003). ${ }^{3}$ Refugees often have access to occupational training, English-language instruction, and support through community organizations (Luthra, Soehl, and Waldinger 2018). In some cases, refugees are offered classes in English and in other labor market skills - e.g., how to search for employment - while housed in temporary facilities even before arrival (FitzGerald and Cook-Martin 2014). In the modern period, refugees also benefit from the fact that they enter the US with legal permanent residence (Portes and Rumbaut 2001; Alba and Nee 2003). By contrast, some economic migrants enter the US without papers; overall, one quarter of the immigrant population is undocumented today (Lopez, et al. 2021). Although, in some cases, financial assistance to refugees is minimal given structural and resource constraints of resettlement agencies (Fee 2019; Fee and Arar 2019; Gowayed 2019), the positive governmental reception and legal status alone may facilitate refugee integration.

Even without access to resettlement programs, migrants who arrive fleeing war or persecution may have distinct integration strategies that differ from migrants who arrive seeking economic opportunity (Cortes, 2004; Becker et al. 2020). Thus, even absent formal assistance, the conditions of refugee migration may shape how refugees respond to social and economic incentives and how they make constrained decisions about their future. First, many refugees do not expect to return to their home country in the years after their arrival given the political conditions that prompted their initial move, whereas economic migrants may return whenever they choose and often plan for a shorter or temporary stay (Cortes 2004; Kosyakova et al. 2022; Gould 1980; Bandiera, et al. 2013). Immigrants who plan to return home make minimal investments in US-specific human capital because they are unlikely to realize the long-term gains (Piore 1979).

\footnotetext{
${ }^{3}$ The segmented assimilation approach highlights the positive governmental reception refugee resettlement programs take. The neo-assimilation approach points to reception institutions and laws that shape purposive action. By pointing to the role of formal institutions and laws, each framework omits the role of capital - human, social, and cultural - in facilitating success among refugees specifically.
} 
By contrast, historical refugee migrants expressed more willingness to invest in their new country by, for example, developing stronger social networks and opening local bank accounts (Anbinder, Ó Gráda, and Wegge, 2019). Second, today's refugees often arrive without a large base of coethnics and therefore have greater exposure to the native-born, although it is not clear that the same pattern was true in the past (Alba and Nee 2003; De Vroome and Van Tubergen 2010). Indeed, many countries today intentionally resettle refugees in dispersed locations to prevent the development of ethnic enclaves, which can slow integration processes (Edin, Fredriksson, Aslund, 2003, Arar and FitzGerald 2022). Economic migrants, by contrast, often arrive with the aid of their social networks and find employment and places to live within enclaves at first arrival (Massey et al. 1987). Refugees who live outside of enclaves may enjoy increased exposure to the native-born, which encourages speaking English and finding employment alongside the native-born (Laliberté, 2019).

The literature suggests that modern refugees may integrate quickly for two main reasons: access to governmental supports and distinct refugee integration strategies. We argue that, if government support is the crucial factor determining refugee success today, we should not see as rapid assimilation for refugee immigrants in the past who did not benefit from governmental assistance or advantages in attaining legal permanent residency. The fact that we do see rapid immigrant assimilation in the past speaks against the central role of governmental supports in supporting refugee assimilation and instead points toward distinct integration strategies deployed by immigrants fleeing persecution.

\section{Linguistic assimilation}

Destination-language acquisition is one of the first steps in the assimilation process. Immigrants must use destination-language in different domains to either get by or get ahead (Fishman 1972, Lieberson 1981, Estrada 2007, Kasinitz et al. 2008). Despite the fact that US policy has never explicitly made English a requirement for entry, the US "is a great destroyer of languages, as sooner or later, English almost always reigns supreme" (Luthra, Soehl, and Waldinger 2018: 211).

Language attainment begins in the immigrant generation. Modern studies find that learning English accelerates upward socioeconomic mobility for immigrants from non-English speaking countries (Bean and Stevens 2003). Destination-language acquisition facilitates skill 
transfers from the sending country and improves interactions with the local population. Contemporary immigrant populations who report being able to speak the destination-country language fluently enjoy higher wages. For instance, Jasso and Rosenzweig (1989) find that, in the US, the ability to speak English is associated with a 10 percent gain in wages relative to immigrants who cannot speak English. Similarly, Dustmann and Fabbri (2003) find that English proficiency is associated with 18-20 percent higher earnings in the UK. Ward (2020) documents that the ability to speak English was also associated with economic success in the early $20^{\text {th }}$ century; immigrants who learned English were 8 percentage points less likely to work in low-paid laborer positions. As such, the first generation learns enough English to get by in various settings and is an important marker of assimilation and integration (Portes and Hao 1998; Espenshade and Fu 1997; Waters and Pineau 2016).

Achieving linguistic fluency is a complex process determined by exposure to the new language, active efforts at language learning, and interactions with personal attributes (including age). Exposure matters: immigrants who live in an enclave receive less exposure to the dominant language and therefore may be less likely to become fluent (Chiswick and Miller 1996, 2001). By contrast, immigrants with a US-born child or US-born spouse may hasten their fluency if these close family members serve as a language teacher (Pagnini and Morgan, 1990; Bean and Stevens 2003; Kuziemko 2014). Even within enclaves, immigrants who know English may enjoy greater status since they are able to bridge contact with the English-speaking world (Morawaska 2004). Beyond exposure, however, the ability to learn a new language is also associated with age at arrival because younger individuals are cognitively better able to learn new languages than are older individuals (Espenshade and Fu 1997; Chiswick and Miller 2001; Bean and Stevens 2003; Bleakley and Chin 2004). School attendance or enrollment in formal language classes in the host society also assists with fluency (Sassler, 2006; Lleras-Muney and Shertzer 2015; Gowayed 2019; Carter 2009; Arendt, et al. 2020).

Refugees may take different pathways to English proficiency than do other immigrants. Several initial factors affecting refugees may place them at an initial disadvantage in language attainment (Kosyakova et al. 2022). Compared to economic migrants, refugees tend to have poorer mental health (van Tubergen and Kalmijn 2005) and may have less pre-migration exposure to the destination-language (Kristen and Seuring 2021). In addition, the labor market orientation of economic migrants may make them more likely to learn a new language to get ahead in the labor 
market. These factors may depress the likelihood that refugees achieve fluency because they can reduce exposure to the destination-language (Kosyakova et al. 2022; Espenshade and Fu 1997).

As noted above, however, refugees are often able to catch-up with economic migrants on a number of social indicators, including language attainment. Refugees may follow distinctive investment strategies because they are less likely to return to their home country. In particular, refugees may experience a stronger incentive to learn a new language because they expect to remain in their new destination for the foreseeable future. Because refugees to the US plan to remain in the country over a longer time horizon, they may be more likely to invest in US-specific human capital such as learning English (Cortes 2004). In addition, modern refugees may enjoy heightened exposure to the destination language if they live in more dispersed locations away from ethnic enclaves. Recent research also suggests that refugees are less likely than other immigrants to maintain cross-national ties, thereby reducing their usage of their mother tongue (Luthra, Soehl, and Waldinger 2017; Morawska 2004). Because refugees may have greater incentives to learn English and are less reliant on their mother-tongue, they may outpace economic migrants in language attainment.

\section{Refugees in the Age of Mass Migration}

Most research on refugees in the United States has been on modern arrivals who entered the country through the official refugee system, which was established in 1980. The Refugee Act of 1980 standardized resettlement support and broadened the scope for admitting more refugees on humanitarian grounds (Zolberg 1988). Before that time, Congress passed some special refugee acts, including the Displaced Persons Act of 1948 (pertaining to refugees from World War II), the Refugee Relief Act of 1953 (pertaining to Eastern Europe) and the Indochina Migration and Refugee Assistance Act of 1975.

Our focus is on an earlier period - the early twentieth century - when the United States did not maintain a formal refugee system, nor did it use periodic refugee acts to authorize access to the country. Instead, (European) immigrants fleeing persecution could enter the country through entry points like Ellis Island much like immigrants arriving for economic reasons or to join family, even if they were not formally designated as refugees. Refugees in this period fled several major events in Europe. Russian Jews fled discrimination and the pogroms, Armenians fled genocide, and dissidents (e.g., communists, Irish nationalists) fled political persecution in many Western 
European countries. Events such as World War I, the Balkan Wars, and the collapse of the Prussian, Ottoman, and Russian empires also greatly contributed to displacement from Europe (Zolberg 1988). Displaced persons made up a higher percentage of the total world population in this historical period than today (Gatrell 2013).

In the past, refugees were not offered targeted English classes by the federal government and thus were required to learn English - if at all - through inter-personal contacts and personal investments in the same manner as economic migrants. At the time, some immigrants relied on family members and children to learn English, while others would learn on-the-job or through night-classes. In addition, some employers, especially large manufacturing firms in the Midwest, required their immigrant workforce to take English classes while on-the-clock, but these classes were not offered differentially by refugee status (Catron 2016). In practice, English was also a requirement to become a citizen in order to answer civics questions posed by a judge; receiving citizenship conferred further economic advantages (Catron 2019). This article seeks to understand refugee linguistic attainment and economic success in a period with little federal support. ${ }^{4}$

\section{Data and Methods}

We gather information on refugee status and English attainment from a novel dataset based on 1,200 oral histories of immigrants who arrived in the US in the early twentieth century, originally conducted by the Statue of Liberty - Ellis Island Foundation (SOLEIF). SOLEIF identified interview subjects by placing advertisements in national magazines and newspapers. In addition, visitors of the Ellis Island Museum who identified themselves or family members as Ellis Island immigrants were given forms to collect basic information. SOLEIF then selected immigrants from this pool to produce the final data set of oral histories. Respondents were interviewed by one of several professional oral historians in a semi-structured manner and prompted to include information about life before and after arrival to the United States. The average interview lasted 54 minutes. All interviews were in English.

\footnotetext{
${ }^{4}$ For more on immigrant assimilation during the Age of Mass Migration, see Morgan, Watkins and Ewbank (1993), Perlmann and Waldinger (1997), Catron (2016, forthcoming), Catron and Vignau Loria (2021), Connor (2020), Abramitzky, Boustan and Eriksson (2014, 2020) and Goldstein and Stecklov (2016).
} 
Each interview asked questions about immigrants' lives, including their life in their home country before migration, experiences going through Ellis Island, and life in the United States after migration. The interviews were conducted when interview subjects were in their 70s and 80s, and therefore collected information on the full life course. The timing of the oral history may introduce recall bias on experiences of migration; we discus robustness to this concern below.

Figure 1 presents a flow chart of our sample construction. The SOLEIF website has posted information about 1,889 individuals; however, 479 of these cases have neither a transcript or audio file extant and 198 interviews were conducted with US-born interviewees (e.g., border agents), leaving us with 1,212 possible individual records. ${ }^{5}$ We collected 972 interviews that had complete audio files and transcriptions directly from the Ellis Island Foundation website, and used an external contractor to transcribe 240 interviews that had audio files but no written transcript. After dropping cases of 22 interviews with multiple respondents (e.g., siblings), our final sample contains 1,190 oral histories.

[Figure 1 Here]

Assigning refugee status and premigration characteristics from oral histories. We assign refugee status based on the stated reason for migration of each individual from their oral history. We note that this approach bears some similarity to the 1951 Refugee Convention and the current definition of a refugee adopted by the United Nations, which includes persons who have a "well-founded fear of persecution" in their home country, and who have been "forced to flee his or her country because of persecution, war or violence" (UNHCR 2021). An advantage of assigning refugee status from a person's perceived experience is that we are able to observe any differences in outcomes between refugees and economic migrants within the same religion or country-of-origin group. Conditions of migrant waves often produce both a refugee flow and an economic flow of people leaving from the same time period and place (Holland and Peters 2020). Assigning refugee status to the individual rather than the group allows us to better understand refugee integration and avoid conflating refugee status with national origin.

${ }^{5}$ The files were retrieved from https://heritage.statueofliberty.org/oral-history-library 
To collect data on refugee status and other pre-migration attributes, we started with an extensive template for 250 interviews that included all potential variables of interest. From these, we created a compressed template that included only well-populated variables. These included: year of arrival in the US, country of origin, religion, urban status before migration, father's occupation in the home country, and stated reason for migration. Religion categories include Catholic, Protestant, Eastern Orthodox, Jewish, and Other/Missing. We employed five research assistants to code these variables in a first round of coding, following pre-defined instructions.

We then worked with two additional research assistances to recode the stated reason for migration variable into two categories (refugee/non-refugee). Double-coding our main variable of interest improves accuracy and allows us to differentiate immigrants who were coded as refugees in both rounds ("refugees") or who were only coded as a refugee in one round ("mixed reason"). We closely supervised our team of research assistants to ensure the integrity of our template and to deal with challenges that arose during the coding process. This supervision involved regular meetings and dialogue between the authors and research assistants. We detail the coding scheme provided to our research assistants in Appendix Table 1. Appendix Figure 1 provides a sample of the transcriptions made by the research assistants in the standardized template.

Coders found classifying reason for migration to be a relatively straightforward task because refugees shared harrowing details about the conditions of their exit. For example, Emilie Adams, a World War I refugee from France, remembers at the age of 5 five avoiding being shot by soldiers by having to "take... a white flag, and...we had to put that flag out before we could come out of the house." Another refugee, Wadih Zogby, lived in Lebanon through the same war. "One third of the population of Lebanon died of starvation or diseases that came after starvation," he recalls. "Once the [sea lanes] opened, about 1920, my brother, who was here [in the United States], kept on writing to us, 'Please come, please come.' And we were very happy to be out, because we suffered like blazes during the First World War."

Economic migrants, on the other hand, often discussed opportunities that the US offered. Lillian Amundson from Finland notes, "then my cousin who had been living in New York City, she came over to Finland to visit her mother and father. And she was telling me how wonderful it is in United States and how easy it is for people to make money when they are willing to work. That's how I got the idea. 'Mother,' I said, 'in Finland I can't help you, but if I go to United States, I will be able to send you money.' And that is how I came..." 
However, in some cases, there were ambiguities about whether individual stories should be classified as refugees or non-refugees. For instance, some immigrants in our sample fled their home countries due to violence or persecution to settle in a second country, and then moved from there to the US at a later date for economic reasons. For instance, during the Russian Revolution in 1917, Samuel Rosen recalls when he was 4 years old, “...you know what a sound, a sewing machine makes? Ta-ta-ta-ta-ta-ta-ta. One day early in morning I asked my mother, 'Why are they using a sewing machine so early in the morning.' She says, 'That's not sewing machines, my boy. That's machine guns being used.' And there was a war going on right, all around us. We stayed sequestered in our houses, we never went out, and we really had a tough time." Samuel's family was able to flee to Romania in 1919 where they lived for five years before making the decision to move to the US for more opportunities and to be closer to family. The 1924 Quota Act stopped that move so they went to Israel instead. Samuel's parents, however, "wanted [the family] to come to the Goldene Medina" and they eventually moved in 1930.

Other immigrants in our sample provide multiple reasons for their move to the US. Theodora Pellegrino describes her first move from Italy to the US in 1912 in economic terms, "Me come this country because everybody in the town talk the America, and they told America nice, America pay more." Theodora returned to Italy to help her sister who lost her husband in WWI. After the Fascist takeover of Italy in 1922, a neighbor falsely accused Theodora and her family of being socialist. As Theodora recalls "Because, see, that time Mussolini give white papers kill...the socialists...See, the Fascists come. One night, see, knock on the door...And twelve o'clock, see, it's bad. And after open the door me, 'What do you want?' 'I want this and them." Theodora convinced the police that she was not a socialist, but then the police began harassing her husband for not enlisting in the military. The family made the decision to move back to the United States soon after. Still others in our sample had already decided to move to the US for economic reasons, but wars or persecution sped up their plans to leave.

Because of these ambiguities, some immigrant stories were classified as 'refugees' by the first round of coding but as 'non-refugees' by the second round of coding. Of the 511 immigrants who arrived as adults and thus form our main analysis sample, there was coder agreement on reason for migration for 411 cases $(=80$ percent $)$ and disagreement for the remaining $100(=20$ percent) of cases. In various specifications, we consider "refugee" and "mixed reason" immigrants 
together, focusing on any immigrant who lists flight from persecution as one reason for their move, or we analyze the two groups separately.

Figure 2 presents two word clouds that may provide insight on the potential topics and words that led coders to classify immigrants as refugees or non-refugees from the entire oral history dataset in our first round of coding. In particular, the figure shows which words are statistically disproportionately associated with refugee and non-refugee oral histories, calculated using Monroe et al. (2008)'s log-odds ratio, informative Dirichlet prior method. For example, refugees are more likely to emphasize words linked to political events such as "war," "revolution," "military" or words related to cultural or religious persecution like "concentration," "camp," and "prison." Economic migrants are more likely to mention words related to economic activity like "farm," "housework" or "cement," or words related to family relations like "dad," and "kids." The words associated with refugee status also make clear that the refugees are more likely to be Jewish ("synagogue" and "kosher" versus "church" and "Christmas").

[Figure 2 Here]

Our sample has good coverage across countries of origin and socio-economic background. Table 1 reports mean attributes of the sample overall, and separately for refugee/mixed reason and economic migrants. For the full sample, 10-20 percent of respondents were born in each of the large European sending countries (Ireland, Germany, Italy, Russia/Poland). The remainder (40 percent) hail from a set of smaller sending countries. Our sample is fairly evenly split by father's occupation, including white-collar positions, manual skilled workers (e.g., tailors, factory workers), farmers and laborers. Relative to economic migrants, refugees tend to arrive in the US at older ages, are more likely to be male, and are more likely to come from urban and white-collar backgrounds.

\section{[Table 1 Here]}

We divide the sample into four arrival periods: 1893-1914, a period of nearly open entry to European immigration; 1915-1923, which covers World War I and the large backlog of immigrants who arrived in the years after the war; 1924-1933, the years after the imposition of 
strict immigration quotas and before the rise of the Nazi regime in Europe, and 1934-1957, a period marked by flight from Nazism, World War II and the Cold War. Figure 3 illustrates the exact year of arrival for refugee and non-refugee immigrants in our sample. Note that 11 percent of our sample immigrated to the US after 1933. Some of these immigrants would have been screened for entry by the 1948 Displaced Persons Act and the 1953 Refugee Relief Act. Although these refugees did not receive formal resettlement assistance, we present robustness results that excludes immigrants who arrived after 1933 below.

[Figure 3 Here]

Members of our sample must survive until at least the 1970s or 1980s in order to be interviewed. As a result, our sample is weighted toward immigrants who arrived at the end of the Age of Mass Migration and who came to the US at younger ages. Because immigrants who arrived as children may have learned English more readily, our main analysis sample includes immigrants who arrived after early childhood (after age 12 or age 14). ${ }^{6}$ Furthermore, 10 percent of our sample hailed from Britain or Ireland, two English-speaking countries, and most of these immigrants would have been fluent in English upon arrival. We drop immigrants from these countries-oforigin in our main analysis.

Relying on retrospective oral histories may produce recall bias. As immigrants age, they may reconstruct their memory of hardship around political oppression or anti-Semitism. American Jewish identity was particularly shaped around collective memories of flight from pogroms and oppression (Zipperstein, 2013). As a result, we present results that split the sample between Jewish and non-Jewish migrants below.

\section{Measures of linguistic attainment from computational linguistics and second-language}

acquisition research. We adapt methods from existing linguistics research to estimate English

\footnotetext{
${ }^{6}$ Our interview subjects who arrived as young children often remark on how quickly they could pick up English. For example, Lucy Attarian who arrived at age 5 recalls "my mother came to visit me in the class a few days later, and the teacher said to her, 'She's really picking it up very well. Just watch her.' Well, she'd asked the children to do something, and of course I'd see them doing it, and I would do the same thing. Not because I understood, but I was following. But it didn't take me long. It didn't take me long at all to pick up the language."
} 
attainment from oral history transcripts. Each oral history contains nearly an hour of actual speech from recorded interviews available both in audio files and as a transcription. After filtering the transcripts to omit very common words (known as "stop words" in computational linguistics, including function words like "the" and "and," as well as pronouns and prepositions), we observe over 1.2 million distinct word tokens across our database of respondents.

Research in second-language acquisition has demonstrated that language proficiency is multifaceted, including aspects of complexity, accuracy, and fluency (Skehan 1998; Ellis and Barkhuizen 2005; Housen, Kuiken, and Vedder 2012). The proficiency of speech can be marked along various dimensions of linguistic structure, including lexical (vocabulary), morphosyntactic (grammar), phonological (sound system), and prosodic (rhythm and intonation).Higher attainment on any of these dimensions may signal to native-speakers a lower degree of foreignness, which may in turn affect treatment in the labor market and other social settings. The use of transcripts and especially the inability to directly interview historical persons limits what we may measure, but here we aim to measure a meaningful subset of the complex variability that constitutes linguistic proficiency and attainment. Our measures have been evaluated by other scholars for their intrinsic associations with attainment, and have been applied in settings such as automated written and spoken assessment (Attali and Burstein 2006; Crossley and McNamara 2012; Kyle et al. 2018; Chen et al. 2018).

Our first measure addresses lexical complexity (vocabulary), relying on the average "age of acquisition" (AoA) of each spoken word, which captures the average age at which any given word is typically learned by native English speakers. The AoA is a measure based on a dictionary from Kuperman et al. (2012), in which each of 30,121 English lemmas (dictionary form of a word) are assigned estimated values of the ages they were learned based on subjective judgments from a large survey. We calculate a person-specific measure as the mean AoA value of all words spoken by the immigrant during their interview. Our second measure captures syntactic complexity by simply calculating the mean length of sentences uttered in an interview, since more complex sentence structures that use dependent clauses and complex phrases tend to be longer. Prior work demonstrates that the use of complex vocabulary and longer sentences are both associated with more proficient speech (Chen and Zechner 2011; Kuperman, Stadthagen-Gonzalez, and Brysbaert 2012; Kyle and Crossley 2015). 
Our third measure, accentedness, captures phonological accuracy and fluency via subjective perceptions of independent evaluators, as coded by three pre-doctoral research assistants who are native speakers of American English. Finally, to supplement this perceptual measure of accentedness, we also calculate immigrants' speech rate in syllables per minute of speech (Riggenbach 1991; Ginther, Dimova, and Yang 2010). Faster speech rate is characteristic of native language speech and increased proficiency, and may interact with perceptions of accentedness in complex ways as speakers negotiate conversational interactions in a non-native language (Derwing 1990; Munro and Derwing 1998; Guion et al. 2000).

We report summary statistics for these four dimensions of speech in Appendix Table 2. In the average transcript, the "age of acquisition" for the average word is close to 5 years of age, and the average sentence is 12 words long. These measures are positively correlated with each other, but the degree of correlation is not high (around 0.3 to 0.4), suggesting that we are picking up independent aspects of language proficiency (Appendix Table 3). These oral histories were collected once for each subject when interviewees were late in life, so we treat these measures as "lifetime attainment." Though proficiency in a language is multidimensional and cannot be fully captured by the four measures used here, our approach offers a much more naturalistic and detailed view of linguistic attainment than typical measures of self-reported fluency.

Figure 4 presents two extracts from the oral history database, reproducing a set of sentences spoken by two Jewish respondents: Morris Helzner ("MH”) and Paul Deutsch ("PD”). To demonstrate how we quantified specific dimensions of speech within our framework, we provide descriptive statistics on depth of vocabulary and sentence length. Morris Helzner uses words that earn high vocabulary scores ("brewing", "hectic") and a longer, more sophisticated sentence structure. Paul Deutsch in contrast, uses shorter and more punctuated sentences with words associated with a lower depth of vocabulary ("father", "stay").

[Figure 4 Here]

We validate our measures of English attainment by documenting the presence of common patterns of proficiency by nationality and age of arrival in the US. First, immigrants who knew English before arrival are likely to have greater English proficiency in our interview sample. Figure 5 shows that immigrants who hailed from English-speaking countries like Great Britain 
have higher measured English attainment by our four measures. Second, as we noted above, there is a well-known pattern by which immigrants who arrive in the US at earlier ages achieve greater English proficiency, either because they are educated in American schools or because they arrive at a "critical age" for language acquisition. The downward slope of each panel suggests that immigrants who arrived at early ages achieved greater English proficiency by our measures than immigrants who arrived later.

[Figure 5 here]

We note some important limitations of our linguistic measures here. First, we only have one interview per immigrant, and so cannot measure individual changes over time. Second, interviews were conducted late in life (median age at interview $=83$ ), and linguistic ability can diminish with general cognitive function (Denis 2016). Third, we rely on speech transcripts to measure vocabulary and syntax. Transcription alone is a complex process of filtering data (JuncosRabadan and Iglesias 1994). Transcribers are particularly likely to be inaccurate in coding speech errors (Ochs 1979), so we do not aim to directly quantify errors such as grammatical agreement mismatches. Fourth, linguistic competence can be task dependent. Accuracy and fluency are foregrounded in personal information exchange tasks like a casual conversation (Skehan 1998), whereas complexity is foregrounded in narrative tasks. Oral history interviews share features with both of these settings but may not reflect a speaker's full linguistic competence. Fifth, our sample of interviews was conducted in English. Although our sample may exclude immigrants who did not achieve a sufficient level of English competency to participate in an interview, we note that the vast majority of immigrants - more than 90 percent - both in the past and today achieve "some" ability to speak English (Lieberson 1981; Alba et al. 2002). Note that many of the interview subjects in our sample speak very halting or imperfect English, and so our results are broadly applicable (but not fully so). Despite these limitations, projecting these methods onto historical data allows researchers to study language use for populations that are no longer alive, and at a scale that would be infeasible with oral proficiency evaluations even for contemporary populations. 
Census linkage. The final step in our data assembly involves extracting standardized economic attributes, such as income and occupation from decennial census data. We used manual record linkage techniques to locate immigrants from the oral history database in the complete-count digitized files of the 1940 Census. Because our sample of oral histories is small relative to the very large datasets usually employed for automated census matching, we use hand-based matching, which has been shown to increase the match rate (Abramitzky, et al. 2021a).

Our hand matches were conducted at the Record Linking Lab of Brigham Young University, considered the "gold standard" of manual record linkage, and were overseen by Joseph P. Price. We are able to hand link 672 male and female immigrants to the 1940 Census, reflecting a 56 percent match rate. A match rate of 56 percent is close to the global maximum given the prevalence of common names, transcription errors and other factors (Abramitzky, et al. 2021a).

The procedure to assemble our hand-based matches mimics the approach used by amateur genealogists when doing research on family members. Linkers were provided with any genealogically relevant information from the oral history transcripts (e.g., first and last names, year of birth, and country of birth). The linker then used this information to create a "mini tree" for the individual on FamilySearch.com, using the search features on the websites FamilySearch and Ancestry.com to find other records for this person. The search algorithms on FamilySearch and Ancestry not only use the standard linkage attributes of name, age and birthplace, but also attributes like the names of family members and places of residence. The use of this additional information provides significant power for distinguishing between individuals with similar names or in identifying individuals even if their name has been misspelled or changed in official records (Price, et al. 2019). Confirmation of possible links are conducted using PDFs of historical census manuscripts. We include one such manuscript (for Morris Helzer) in Appendix Figure 2.

As is standard and expected for historically linked samples, our matched sample is not fully representative of the universe of records under consideration (here: the Ellis Island database). Appendix Table 4 enumerates the differences between observations in the Ellis Island sample that matched or did not match to the Census. We match a greater proportion of immigrants born in Italy and a lower proportion of immigrants born in Germany or Austria. Often, differences in match rates by country of origin reflect variation in the commonness of first or last names. Immigrants with more common names are less likely to generate a unique match to the Census. Likely because 
of country-of-origin differences, our matched immigrants are more likely to be Catholic and were more likely to arrive in the US before the border closure.

Table 2 reports average socio-economic characteristics for the immigrants that we can link to the Census by refugee status. The modal year of completed schooling is 8-9 years. 44 percent of our sample attended at least one year of high school, and 11 percent attended at least one year of college. Refugee/mixed reason immigrants completed more schooling than economic migrants, with 56 percent attending at least one year of high school. Around one third of the sample held a white-collar occupation in 1940 and half of the sample earned more than $\$ 1,000$ in 1940 dollars (around \$18,000 in 2019 dollars). Refugees earned more than non-refugees in 1940, with 61 percent earning more than $\$ 1,000$. We weight results based on the linked sample to account for differences between the linked sample and the population.

Income data is either missing or zero in 1940 for 57 percent of our linked sample, both because most women in the sample do not have reported income and because self-employment income was not recorded in the 1940 Census. We can expand the number of observations with an economic outcome by using the imputed "income score" introduced in Abramitzky, et al. (2021b). The income score predicts income based on occupation, along with gender, a quadratic in age, birthplace and state of residence using the 1940 Census. The income score is an expanded version of measures like the "occupation score" provided by IPUMS which is based only on median income within an occupation and does not consider other relevant information like region or age.

\section{[Table 2 Here]}

New Immigrant Survey Data. We use data from the New Immigrant Survey (NIS) to compare the English attainment of refugees in the past with refugees in the modern period. The NIS is a nationally representative multi-year survey of new legal immigrants to the US. We focus on the first survey wave, a random sample of adults receiving legal permanent residence between May and November of 2003. The survey includes immigrants who arrived in the US as refugees or asylum seekers; we classify both of these arrival types as 'refugees.' From the NIS, we obtain information on whether an immigrant speaks any English or speaks English "well." Note that, as is typical in modern datasets, we do not have access to the same detailed level of information on English proficiency in the NIS as we do for the historical oral histories. Thus, we view the NIS 
results as a pilot study for the modern period and encourage future work collecting and analyzing transcripts of immigrant speech. We can control in the NIS data for country of origin, year of departure from country of origin, gender, age, religion, years of schooling prior to immigration, and number of English classes taken within the last year and prior to arrival in the US.

Appendix Table 5 reports summary statistics for immigrants in the NIS data by refugee status. Refugees are more likely to speak any English at the time of survey (85 percent vs. 74 percent), but they are less likely to speak English well (33 percent vs. 39 percent). Refugees are also more likely to have taken an English class in the past year, perhaps because of government supports, but they are less likely to have taken an English class before moving to the US. Refugees are reasonably well balanced relative to non-refugee migrants on attributes like gender, age and education, but are notably more likely to have moved from Europe/Central Asia or from Russia, Ukraine or Poland (total $=62$ percent vs. 16 percent). This geographic pattern reflects refugee priorities for the US in the immediate aftermath of the Cold War and the aftermath of the Bosnian War as immigrants in the sample arrived in the US in the late 1990s and early 2000s.

Estimation strategy. Our analysis rests on a series of multiple regression models. Each observation is an immigrant drawn from the Ellis Island oral histories. In the second part of our analysis, we limit our attention to the subsample that can be linked to the 1940 census.

We start by considering the relationship between refugee status and English proficiency. In particular, we estimate models of the following form:

$$
y_{i}=\beta_{1} R E F U G E E_{i}+\beta_{k} X_{k}+\epsilon_{i}
$$

where the dependent variables $y_{i}$ are one of the four linguistic measures (vocabulary, syntax, accentedness or syllables per minute) and the main right-hand side variable is an indicator for whether the immigrant reports leaving their sending country for non-economic reasons, such as a flight from persecution or violence $\left(R E F U G E E_{i}\right)$. In our first model, we include any immigrant who mentions flight from persecution as one of their reasons for moving into the REFUGEE indicator, combining both refugees and "mixed reason" movers. In our second model, we create two indicator variables $\left(R E F U G E E^{l}{ }_{i}\right.$ and $\left.R E F U G E E^{2}{ }_{i}\right)$, with $R E F U G E E^{l}{ }_{i}$ equal to one for refugees classified as such in both rounds of coding, and $R E F U G E E^{2}{ }_{i}$ equal to one for immigrants who had 
mixed reasons for moving and were classified as a refugee by either round 1 or round 2 of coding, but not both. Note that, in both cases, the comparison group includes any immigrant who was never marked as a refugee; that is, for immigrants in the comparison group, both round 1 and round 2 coders consider this immigrant to have moved to the US for economic or family reasons.

The regression also includes a vector of controls $(X)$ that include age and age squared, gender, an indicator for arrival period (before 1924, 1924-33, 1934-after), an indicator for country of birth, and - in some specifications - controls for other aspects of pre-migration environment, including indicators for religion, father's occupation in the sending country and urban status. For this analysis, we focus on immigrants who arrived after early childhood (after age 12) because the process of language acquisition is different - and often more immediate - for immigrants who arrive as young children. We also consider robustness for different cutoffs of when 'early childhood' ends.

We then document that our measures of English proficiency are correlated with economic outcomes at mid-life using variables collected from the links to the US Census. We estimate regression models of the following form:

$$
Y_{i}=\beta_{1} \text { English }_{i}+\beta_{k} X_{k}+\epsilon_{i}
$$

where the dependent variable $Y_{i}$ is the logarithm of annual earnings or of the income score. Our main right-hand side variables of interest are one of the four primary measures of English proficiency (English): vocabulary, syntax, accent or fluency/speed. Controls in the vector $X$ include age and age squared, gender, indicators for country of birth, and indicators for decade of arrival. This analysis is based on the 287 observations of interviews that we were able to link to the 1940 Census linked sample with a reported income (or the 363 observations with the information needed to calculate income score). The temporal ordering of our measures prevents us from making any strong claims about the causal relationship between English proficiency and economic status, given that English ability is only measured later in life. 


\section{Results}

Refugees achieved higher levels of English proficiency than economic migrants in the past. We start by estimating the relationship between refugee status and English attainment in our historical dataset.

We find that immigrants who left Europe for the US under duress in the early twentieth century achieved a higher level of English proficiency by the end of life, particularly in terms of building a deeper English vocabulary. Figure 6 presents coefficients on an indicator variable that includes immigrants coded as a refugee by at least one coder (both refugees and "mixed reason" immigrants). Figure 7 instead presents coefficients on two indicators: one for being coded as a "refugee" and one for being coded as moving for "mixed reasons." The solid colored diamonds reflect results from a set of basic regressions that control only for a quadratic in age, and indicators for arrival period, country of birth and gender.

In both models, immigrants fleeing from persecution achieved a greater depth of vocabulary, scoring 0.4 standard deviations higher on our "Age of Acquisition" score. This relationship holds for both refugees and "mixed reason" immigrants in Figure 7. Refugee immigrants also have more complex sentence syntax, although this relationship is not present for "mixed reason" immigrants and appears to be driven by pre-migration attributes of refugees, who are more likely to hail from white collar and urban backgrounds. After controlling for these characteristics, the association between refugee status and mean sentence length substantially weakens.

Refugee migrants are no more able than economic migrants to eliminate their accent and do not utter more syllables per minute. This pattern is consistent with existing results that while grammar and lexis (vocabulary) are subject to fewer maturational constraints, learning how to pronounce new phonemes becomes markedly more challenging with age and is thus less mutable or responsive to investment, commonly called "the Conrad phenomenon" in the field of linguistics (Patowski 1990; Bongaerts et al. 1997; Moyer 1999).

We reject the hypothesis that the initial selection of immigrants fleeing persecution might explain why they achieve a greater depth of English vocabulary by the end of life. The open colored diamonds present coefficients from regressions that add an expanded set of controls, including indicators for childhood religion, being raised in an urban area, and father's occupation. Refugees and "mixed reason" immigrants in our sample are more likely to be Jewish, more likely to be raised 
in an urban area, and more likely to hail from a household headed by a white-collar worker, as opposed to a farmer or laborer. Adding these controls moderates the positive association between refugee migrants and English vocabulary to a small degree, but we still observe a strong refugee advantage on this measure. We report the coefficients from the regressions underlying Figure 6 in Appendix Table 6.

[Figure 6 Here]

One concern is that refugees have greater measured vocabulary simply because talking about persecution requires a more complex set of words. That is, the construction of our Age of Acquisition measure could be systematically biased by the use of words that align with specific topics of conversation. Most notably, a migrant's description of fleeing persecution or of a particular historical event could evoke the use of more sophisticated words (e.g. "affidavit," "revolution" "government"; see Figure 2). If true, this relationship could bias our analysis toward finding a positive correlation between the Age of Acquisition measure and refugee status. To address this issue, we create an alternative vocabulary measure that is calculated after dropping persecution-related words from interview transcripts. We defined persecution related words through the manual inspection of thousands of the most common words in our transcripts. A second set of estimates in Figure 6 and Figure 7 (orange diamonds) confirms that our analyses are robust to the omission of a large list of words that are specifically tied to persecution and conflict, which otherwise could artificially distort the association between refugee status and English proficiency (see the list of words in Appendix Table 7).

[Figure 7 here]

We emphasize that our results do not depend on comparing English attainment across groups (e.g., Jews and non-Jews). Rather, we are comparing the linguistic proficiency of refugees and economic migrants from the same country-of-origin and religious group. For example, our specification compares a Jewish migrant leaving the Russian Empire in the 1900s under threat of persecution to another Jewish migrant from the Russian Empire in this period who reports migrating to find employment or to reunite with family. We also make similar contrasts within the 
non-Jewish population (e.g., a German Catholic fleeing from war versus a German Catholic moving for economic opportunity).

In order to confirm that our results are not driven by the Jewish population, we conduct the analysis on sub-sets of the data. Figure 8 splits the sample into Jewish and non-Jewish immigrants. We find a similar association between refugee status and English attainment in both groups, illustrating that the findings are not being driven by one group alone. If anything, the association between refugee status and vocabulary is stronger for the non-Jewish sample. As we mentioned above, American Jewish identity has developed around a collective memory of persecution in the old country (Zipperstein, 2013). Recall bias on the part of Jewish migrants may have overemphasized the harsh conditions leading to their departure. Alternatively, all/most Jewish immigrants in this period, even those who report economic concerns as their proximate reason for migration, may have been somewhere on the continuum of coercion given the intensity of antiJewish violence at the time. Either force could be attenuating the results in the Jewish subsample.

[Figure 8 here]

Our results are not dependent on specifics of sample selection. Appendix Figure 3 show that results are unchanged if we conduct our analysis on the full sample, including immigrants from English speaking countries (e.g., Britain). One particularly distinctive refugee flow is the select group of German and Eastern European refugees who fled from the Nazi regime and the advancement toward war in the 1930s. This group included many scientists, authors and industrialists who may have arrived with particularly high levels of education or capacity to learn English. Appendix Figure 4 show that our vocabulary results are robust to excluding immigrants who arrived after the rise of Nazism in 1933, some of whom were accepted under special refugee acts in 1948 and 1953. However, the association between refugee status and syntax (mean sentence length) disappears. As we noted above, this association seems to be driven by pre-migration characteristics of refugees (higher initial socio-economic status). In Appendix Figure 5, we adjust the definition of arriving in adulthood from arriving after age 12 to arriving after age 14. Results are qualitatively similar. 
Higher English attainment is associated with higher earnings for immigrants in the past. We next examine the association between English proficiency and socio-economic success. These analyses allow us to show that our linguistic measures are associated with theoretical expectations of linguistic incorporation (Bean and Stephens 2003; Fishman 1972; Alba and Nee 2003).

We estimate a series of regression models where the dependent variable is the logarithm of income and the independent variables are the measures of depth of vocabulary (Age of Acquisition score), syntax (mean sentence length), accentedness, and syllables per minute. This analysis is based on immigrants whom we can link to the 1940 US Census. We start by considering individual income data, which is available for 277 of the 672 linked observations. We then turn to our income score measure imputed from occupation and other attributes; this income proxy is available for 341 observations. All models include standard demographic controls.

Figure 9 considers the association between income and our measures of English attainment. For comparability, variables are standardized to have a mean of zero and a standard deviation of one. A one standard deviation increase in English vocabulary, syntax or accentedness is associated with a 30-40 percent higher income. For comparison, Appendix Table 8 shows that the widely-studied Census measure of English fluency (an indicator for speaking English) is likewise associated with a 16 percent increase in income. ${ }^{7}$ Our detailed measures of vocabulary and syntax suggest that English ability is substantially more important for economic outcomes than standard measures would imply.

[Figure 9 here]

Appendix Figure 6 reproduces the results for our detailed measures of English proficiency using the income score - an imputed measure of earnings based on age, birthplace, state of residence and occupation - rather than reported income as an outcome variable. Using the income score allows us to expand to a larger sample, and also adjusts for annual variation in income. We continue to find a strong association between vocabulary and syntax and this occupation-based

\footnotetext{
7 The English census variable is not available in the 1940 census. We therefore calculate the association of English fluency and economic outcomes using a matched sample of immigrants using the 1930 and 1940 censuses. To match these censuses of all immigrants, we use automated methods used in prior work (Abramitzky et al. 2021; Catron 2019, 2020).
} 
proxy for income, but we no longer see an association with accent. It appears that accent raises income within occupational titles, but does not shift immigrants between occupations.

As noted, we measure income and occupation at mid-career, while our measures of linguistic proficiency are gathered later in life. Given this timing, we do not know whether the immigrants in our sample earned more because of their language skills or, perhaps alternatively, deepened their knowledge of English on the job. However, the literature in linguistics about second language acquisition, there is a broad consensus on the presence of a "critical period" in language learning, in which gains in proficiency peak at some point in the teenage years (e.g., Hartshorne, Tenenbaum, and Pinker 2018; for a broader review see Birdsong 2018). While there are extensive debates on the exact timing of such a period, and we do not know when the immigrants in our sample learned English, it is likely that much of the language we observe later in life was present at mid-career.

The English proficiency of refugee migrants today. We next compare our historical findings to the best available source of modern data on the refugee population - the New Immigrant Survey (NIS). We estimate the relationship between refugee status and two measures of English attainment - whether an immigrant speaks any English, and whether an immigrant speaks English well. Note that we do not have detailed information on English proficiency in the modern data.

We find a similar pattern today as in the past, whereby refugees are more likely than other legal permanent residents to report speaking some English. Panel A of Table 3 shows the coefficients on the indicator variable for being a refugee migrant. We start in column (1) by including a basic set of demographic controls (age, gender, year of migration to the US and country of origin). After we adjust for differences in socio-economic background, we find that refugee migrants are 8 percentage points more likely to speak some English relative to similar non-refugee migrants. In column (2), we introduce socio-economic controls, including years of schooling prior to immigration, whether an immigrant previously lived in a rural or urban area, and religion.

In the modern context, refugee migrants may receive more government supports, including subsidized or free English classes (indeed, we find in Appendix Table 5 that refugees are more likely to have taken a recent English class). In column (3) we control for taking a recent English class or an English class before arrival. We continue to find that refugees are more likely than non- 
refugees to speak some English, suggesting that the heightened attainment achieved by refugees in the modern period occurs above and beyond any access to common government supports.

Lastly, given that our historical analysis examines immigrant English attainment that occurred over several decades, we restrict our modern sample to immigrants who have lived in the US for at least two years, shown in column (4). We find a similar result, that refugees are more likely to speak some English relative to non-refugee migrants. This result aligns with other studies that find refugees in the US today experience rapid improvements in (self-reported) English proficiency with time spent in the country (Cortes 2014; Chin and Cortes 2015).

Panel B repeats the analysis for speaking English 'well,' rather than speaking some English. Before adding socio-economic controls, it appears that refugees are less likely than nonrefugee migrants to speak English well. Some of these differences in English ability may reflect pre-migration differences in exposure to English (refugees are less likely to report taking an English class before immigration; see Appendix Table 5). Indeed, after adding controls for premigration background, we find no significant relationship between refugee status and the likelihood that an immigrant speaks English well.

\section{Discussion/Conclusion}

The special case of refugee integration has been of considerable importance to theories of assimilation. Scholars often point to contemporary refugees to highlight the positive impact of governmental programs on assimilation and integration. However, many immigrants today (and certainly in the past) arrived having fled similar conditions, but are not labeled as official refugees and thus do not qualify for assistance (Garcia et al. 2021; Hamlin 2021). Because prior studies assign refugee status to groups instead of individuals, little is known about those who do not benefit from federal assistance, but otherwise may fear returning home.

Our analysis reveals that, even in the past, a period without government support for refugees, immigrants who moved to the US to escape from persecution or war achieved greater English proficiency as measured by depth of vocabulary than immigrants who moved to pursue economic opportunity. This pattern holds even after controlling for country of origin, arrival period, and religion, thereby comparing refugees to economic migrants within the same national origin or ethnic group. Our analysis of modern refugees reinforces this point, demonstrating that refugees have greater English proficiency today even after controlling for opportunities to enroll 
in English classes. Taken together, this pattern implies that the success of refugee immigrants in the United States is a long-run feature of the country's history.

Our study demonstrates that the refugee advantage occurred in a historical and modern period without resettlement assistance or controlling for it. This finding suggests that refugees themselves engage in behaviors, either intentionally or unintentionally, that improve their linguistic proficiency (Alba and Nee 2003). Many refugees do not expect to be able to return home in the near term. Faced with this situation, refugees may therefore be more likely to invest in USspecific human capital, relying on the American educational system and the open labor market, to find employment, housing, and social networks, leading ultimately to greater English-language attainment.

Immigrants who were pushed from Europe by persecution or war were drawn from higher socio-economic status backgrounds than immigrants who left to seek economic opportunity. This pattern may suggest that refugee migrants arrive with a higher aptitude to acquire English skills (Shin and Alba 2009; Aksoy and Poutvaara 2019). However, we document that the association between refugee migration and depth of vocabulary changes very little after controlling for father's pre-migration occupation and urban status.

Some forces of migrant selection could push in the opposite direction. Economic migrants who are unsuccessful in their new destination may be more likely than refugees to return home. Previous research finds that return migrants were "negatively selected," in the sense that they were drawn from lower-paying occupations (Borjas and Bratsberg 1994; Abramitzky, Boustan, and Eriksson 2019). As a result, the economic migrants who remain in our sample may have been higher-skilled or more successful than the full population of economic migrants, and thus their linguistic attainment is likely biased upward. Yet, despite this possible upward bias, we continue to find that refugees achieve more English proficiency, suggesting that refugees would likely look even more accomplished relative to the full population of economic migrants.

Our paper builds on existing work in historical sociolinguistics utilizing oral histories as a source of data (Heller and Mumma 2020). We suggest new ways to apply measures developed in linguistic research to the study of historical records at a large scale. Our approach can be extended to other sources of qualitative immigration data including historical archives of immigrants' letters, diaries, and other oral history collections as well as more contemporary sources of qualitative data. 
These rich data sources may help future researchers explore other aspects of language acquisition, including reading and writing abilities.

\section{References}

Abramitzky, Ran, and Leah Boustan. 2017. "Immigration in American Economic History." Journal of Economic Literature.

Abramitzky, Ran, Leah Boustan, and Katherine Eriksson. 2014. "A Nation of Immigrants: Assimilation and Economic Outcomes in the Age of Mass Migration." Journal of Political Economy 122(3): 467-517.

Abramitzky, Ran, Leah Boustan, and Katherine Eriksson. 2019. "To the New World and Back Again: Return Migrants in the Age of Mass Migration.” ILR Review 72 (2): 300-322.

Abramitzky, Ran, Leah Boustan, and Katherine Eriksson. 2020. "Do Immigrants Assimilate More Slowly Today Than in the Past?" American Economic Review: Insights 2(1): 125141.

Abramitzky, R., Boustan, L. P., \& Connor, D. (2020). "Leaving the enclave: Historical evidence on immigrant mobility from the industrial removal office" National Bureau of Economic Research (No. w27372).

Abramitzky, Ran, Leah Boustan, Katherine Eriksson, James Feigenbaum, and Santiago Pérez. 2021a. "Automated Linking of Historical Data." Journal of Economic Literature 59(3): 865-918.

Abramitzky, Ran, Leah Boustan, Elisa Jacome, and Santiago Perez. 2021b. "Intergenerational Mobility of Immigrants in the United States over Two Centuries." American Economic Review 111 (2): 580-608.

Adda, Jérôme, Christian Dustmann, and Joseph-Simon Görlach. 2020. "The Dynamics of Return Migration, Human Capital Accumulation, and Wage Assimilation." Unpublished Manuscript.

Akresh, Illana Redstone. 2008. "Occupational Trajectories of Legal U.S. Immigrants: Downgrading and Recovery." Population Development Review 34(3): 435-456.

Aksoy, Cevat Giray, and Panu Poutvaara. 2019. "Refugees' Self-Selection into Europe: Who Migrates Where?” SSRN Electronic Journal.

Alba, Richard D. and Victor Nee. 2003. Remaking the Mainstream: Assimilation and Contemporary Immigration. Harvard University Press.

Alba, Richard, John Logan, Amy Lutz, and Brian Stults. 2002 "Only English by the Third Generation? Loss and Preservation of the Mother Tongue among the Grandchildren of Contemporary Immigrants." Demography 39, no. 3: 467-484. 
Anbinder, T., Gráda, C. Ó., \& Wegge, S. A. (2019). Networks and Opportunities: A Digital History of Ireland's Great Famine Refugees in New York. American Historical Review, 124(5), 1591-1629.

Arar, Rawan, and David FitzGerald. Forthcoming. Refugees: A Sociological Systems Approach. Polity.

Arendt, Jacob Nielsen, Iben Bolvig, Mette Foged, Linea Hasager, and Giovanni Peri. 2020. "Integrating Refugees: Language Training or Work-First Incentives?" National Bureau of Economic Research Working Paper.

Attali, Y., \& Burstein, J. (2006). Automated essay scoring with e-rater ${ }^{\circledR}$ V. 2. The Journal of Technology, Learning and Assessment, 4(3).

Aydemir, Abdurrahman. 2011. "Immigrant Selection and Short-Term Labor Market Outcomes by Visa Category." Journal of Population Economics 24 (2): 451-75.

Bakker, Linda, Jaco Dagevos, and Godfried Engbersen. 2017. "Explaining the Refugee Gap: A Longitudinal Study on Labour Market Participation of Refugees in the Netherlands." Journal of Ethnic and Migration Studies 43 (11): 1775-91.

Bandiera, Oriana, Imran Rasul, and Martina Viarengo. 2013. "The Making of Modern America: Migratory Flows in the Age of Mass Migration." Journal of Development Economics 102: $23-47$.

Bean, Frank D., and Gillian Stevens. 2003. America's Newcomers and the Dynamics of Diversity. Russell Sage Foundation.

Becker, Sascha O., Irena Grosfeld, Pauline Grosjean, Nico Voigtlander, and Ekaterina Zhuravskaya. 2020. "Forced Migration and Human Capital: Evidence from Post-WWII Population Transfers.” American Economic Review 110 (5): 1430-63.

Bevelander, Pieter. 2016. "Integrating Refugees into Labor Markets: Economic Integration of Refugees into their Host Country is Important and Benefits Both Parties." IZA World of Labor 259: 1-9.

Bleakley, H. and Chin, A., 2004. "Language Skills and Earnings: Evidence from Childhood Immigrants." Review of Economics and statistics, 86(2), pp.481-496.

Bloemraad, Irene. 2006. Becoming a citizen: Incorporating immigrants and refugees in the United States and Canada. Berkeley, CA: University of California Press.

Bongaerts, Theo, Chantai van Summeren, Brigitte Planken, and Erik Schils. 1997. "Age and ultimate attainment in the pronunciation of a foreign language." Studies in second language acquisition, 447-465.

Borjas, George J., and Bernt Bratsberg. 1994. "Who Leaves? The Outmigration of the Foreign Born.” National Bureau of Economic Research Cambridge, Mass., USA. 
Carter, Linda Kay. 2009. "Evening Schools and Child Labor in the United States, 1870-1910." $\mathrm{PhD}$ Thesis.

Catron, Peter. 2016. "Made in America? Immigrant Occupational Mobility in the First Half of the Twentieth Century." American Journal of Sociology 122(2): 325-378.

Catron, Peter. 2019. "The Citizenship Advantage: Immigrant Socioeconomic Attainment across Generations in the Age of Mass Migration." American Journal of Sociology 124(4): 9991042

Catron, Peter. 2020. "The Melting-Pot Problem? The Persistence and Convergence of Premigration Socioeconomic Status in the Age of Mass Migration.” Social Forces 99(1): 398-423.

Catron, Peter. Forthcoming. "The Alien Citizen: Social Distance and the Economic Returns to Naturalization" Social Problems

Catron, Peter, and Maria Vignau Loria. 2021. "The Economic Attainment of Mexican Refugees During the Age of Mass Migration.” SocArXiv.

Chen, Miao, and Klaus Zechner. 2011. "Computing and Evaluating Syntactic Complexity Features for Automated Scoring of Spontaneous Non-Native Speech.” Proceedings of the 49th Annual Meeting of the Association for Computational Linguistics: Human Language Technologies.

Chen, L., Zechner, K., Yoon, S. Y., Evanini, K., Wang, X., Loukina, A., ... \& Gyawali, B. (2018). Automated scoring of nonnative speech using the speechrater sm v. 5.0 engine. ETS Research Report Series, 2018(1), 1-31.

Chin, Aimee, and Kalena E. Cortes. 2015. "The Refugee/Asylum Seeker." In Handbook of the Economics of International Migration, 1:585-658. Elsevier.

Chiswick, Barry R., and Paul W. Miller. 1996. "Ethnic Networks and Language Proficiency among Immigrants.” Journal of Population Economics 9 (1): 19-35.

Chiswick, Barry R., and Paul W. Miller. 2001. "A Model of Destination-Language Acquisition: Application to Male Immigrants in Canada.” Demography 38 (3): 391-409.

Connor, Dylan Shane. 2020. Class background, reception context, and intergenerational mobility: A record linkage and surname analysis of the children of Irish immigrants. International Migration Review, 54(1), 4-34.

Connor, Phillip. 2010. "Explaining the Refugee Gap: Economic Outcomes of Refugees versus Other Immigrants." Journal of Refugee Studies 23 (3): 377-97.

Cortes, Kalena E. 2004. "Are Refugees Different from Economic Immigrants? Some Empirical Evidence on the Heterogeneity of Immigrant Groups in the United States." Review of Economics and Statistics 86 (2): 465-80. 
Crossley, S. A., \& McNamara, D. S. (2012). Predicting second language writing proficiency: The roles of cohesion and linguistic sophistication. Journal of Research in Reading, 35(2), 115-135.

De Vroome, Thomas, and Frank Van Tubergen. 2010. "The Employment Experience of Refugees in the Netherlands." International Migration Review 44 (2): 376-403.

Denis, Derek. 2016. "Oral Histories as a Window to Sociolinguistic History and Language History: Exploring Earlier Ontario English with the Farm Work and Farm Life since 1890 Oral History Collection." American Speech 91 (4): 513-16.

Derwing, Tracey M. 1990. "Speech Rate Is No Simple Matter: Rate Adjustment and NS-NNS Communicative Success." Studies in Second Language Acquisition 12 (3): 303-13.

Donato, Katharine M., and Elizabeth Ferris. 2020. "Refugee Integration in Canada, Europe, and the United States: Perspectives from Research." The ANNALS of the American Academy of Political and Social Science 690 (1): 7-35.

Dustmann, Christian, and Joseph-Simon Görlach. 2016. "The Economics of Temporary Migrations." Journal of Economic Literature 54 (1): 98-136.

Dustmann, Christian, and Francesca Fabbri. 2003. "Language Proficiency and Labour Market Performance of Immigrants in the UK." The Economic Journal 113(489): 695-717.

Edin, Per-Anders, Peter Fredriksson, and Olof Åslund. 2003. "Ethnic Enclaves and the Economic Success of Immigrants: Evidence from a Natural Experiment." Quarterly Journal of Economics 118, no. 1: 329-357.

Ellis, Rod, and Gary Barkhuizen. 2005. Analysing Learner Language. Oxford: Oxford University Press.

Espenshade, Thomas J., and Haishan Fu. 1997. "An Analysis of English-Language Proficiency among US Immigrants." American Sociological Review, 288-305.

Estrada, Vanesa. 2007. "Language." In The New Americans: A Guide to Immigration since 1965, edited by Mary Waters and Reed Ueda. Cambridge: Harvard University PRess

Evans, William N., and Daniel Fitzgerald. 2017. "The Economic and Social Outcomes of Refugees in the United States: Evidence from the ACS." National Bureau of Economic Research.

Fasani, Francesco, Tommaso Frattini, and Luigi Minale. 2020. "Lift the Ban? Initial Employment Restrictions and Refugee Labour Market Outcomes."

Feigenbaum, James J. and Hui Ren Tan. 2020. "The Return to Education in the Mid-Twentieth Century: Evidence from Twins." The Journal of Economic History 80(4): 1101-1142

Fee, Molly, and Rawan Arar. 2019. "What Happens When the United States Stops Taking in Refugees?" Contexts 18(2): 18-23. 
Fee, Molly. 2019. "Paper Integration: The Structural Constraints and Consequences of the US Refugee Resettlement Program." Migration Studies 7(4): 477-495.

Fischer, Claude S., and Michael Hout. 2006. Century of Difference: How America Changed in the Last One Hundred Years. Russell Sage Foundation.

Fishman, Joshua A. 1972. The Sociology of Language. Rowley, MA: Newbury House

FitzGerald, David Scott, and Rawan Arar. 2018. "The Sociology of Refugee Migration.” Annual Review of Sociology 44: 387-406.

FitzGerald, D.S., 2014. Culling the Masses: The Democratic Origins of Racist Immigration Policy in the Americas. Harvard University Press.

Flores, R.D., 2017. "Do Anti-Immigrant Laws Shape Public Sentiment? A Study of Arizona's SB 1070 using Twitter Data" American Journal of Sociology, 123(2), pp. 333-384.

Friedberg, Rachel M. 2000. "You Can't Take It with You? Immigrant Assimilation and the Portability of Human Capital." Journal of Labor Economics 18 (2): 221-51.

Garcia, Angela S., Yunuen Rodriguez-Rodgriguez, and Juan Contreras. 2021. "Violence Here and Violence There: How Compound Violence Drives Undocumented Mexicans' Migration to and Settlement in the United States." Journal of Immigrant and Refugee Studies

Garip, Filiz. 2016. On the Move: Changing Mechanisms of Mexico-U.S. Migration. Princeton University Press.

Gatrell, Peter. 2013. The Making of the Modern Refugee. OUP Oxford.

Ginther, April, Slobodanka Dimova, and Rui Yang. 2010. "Conceptual and Empirical Relationships between Temporal Measures of Fluency and Oral English Proficiency with Implications for Automated Scoring." Language Testing 27 (3): 379-99.

Goldstein, Joshua R. and Guy Stecklov. 2016. "From Patrick to John F.: Ethnic Names and Occupational Success in the Last Era of Mass Migration." American Sociological Review 81(1): 85-106.

Gould, J. D. 1980. "European Inter-Continental Emigration. The Road Home: Return Migration from the USA." Journal of European Economic History 9 (1): 41.

Gowayed, Heba. 2019. "Diverging by Gender: Syrian Refugees' Divisions of Labor and Formation of Human Capital in the United States." Gender and Society 33(2): 251-272.

Guion, Susan, James Flege, Serena Liu, and Grace Yeni-Komshian. 2000 "Age of Learning Effects on the Duration of Sentences Produced in a Second Language." Applied Psycholinguistics 21(2): 205-228.

Hamlin, Rebecca. 2021. Crossing: How We Label and React to People on the Move. Stanford University Press. 
Hartshorne, Joshua K., Joshua B. Tenenbaum, and Steven Pinker. 2018. "A Critical Period for Second Language Acquisition: Evidence from 2/3 Million English Speakers." Cognition 177: 263-277.

Heller, Blake, and Kirsten Slungaard Mumma. 2020. "Immigrant Integration in the United States: The Role of Adult English Language Training."

Holman, Philip. 1996. "Refugee Resettlement in the United States." In Haines, Refugees in American in the 1990s: A Reference Handbook. Pp 3-27. Westport, CT: Greenwood Press.

Holland, Alisha C. and Margaret E. Peters. 2020. "Explaining Migration Timing: Political Information and Opportunities." International Organization 74(3): 560-583.

Housen, Alex, Folkert Kuiken, and Ineke Vedder. 2012. Dimensions of L2 Performance and Proficiency: Complexity, Accuracy and Fluency in SLA. Vol. 32. John Benjamins Publishing.

Jasso, Guillermina and Mark Rosenzweig. 1989. "Language Skill Acquisition, Labor Markets and Locational Choice: The Foreign-Born in the United States, 1900 and 1980." In Migration and Labor Market Adjustment (pp. 217-239). Springer, Dordrecht.

Jasso, Guillermina and Mark Rosenzweig. 1990. The New Chosen People: Immigrants in the United States. Russell Sage Foundation.

Jimenez, Tomas. 2011. Immigration in the United States: How Well Are They Integrating into Society? The Migration Policy Institute.

Juncos-Rabadán, Onésimo, and Francisco Iglesias. 1994. "Decline in the Elderly's Language: Evidence from Cross-Linguistic Data.” Journal of Neurolinguistics 8 (3): 183-90.

Kasinitz, Philip, John Mollenkopf, Jennifer Holdaway, and Mary Waters. 2009. Inheriting the City: The Children of Immigrants Come of Age. Harvard University Press.

Kuperman, Victor, Hans Stadthagen-Gonzalez, and Marc Brysbaert. 2012. "Age-of-Acquisition Ratings for 30,000 English Words.” Behavior Research Methods 44 (4): 978-90.

Kosyakova, Yuliya, Cornelia Kristen, and Christoph Spörlein. 2022. "The Dynamics of Recent Refugees' Language Acquisition: How Do Their Pathways Compare to Those of Other New Immigrants?." Journal of Ethnic and Migration Studies 48(5): 989-1012.

Kristen, C. and Seuring, J., 2021. "Destination-language Acquisition of Recently Arrived Immigrants: Do Refugees Differ From Other Immigrants?.” Journal for Educational Research Online, 13(1), pp.128-156.

Kuziemko, Ilyana. 2014. "Human Capital Spillovers in Families: Do Parents Learn from or Lean on Their Children?" Journal of Labor Economics 32(4): 755-786

Kyle, K., Crossley, S., \& Berger, C. 2018. "The Tool for the Automatic Analysis of Lexical Sophistication (TAALES): Version 2.0.” Behavior Research Methods, 50(3), 1030-1046. 
Kyle, Kristopher, and Scott Crossley. 2015. "Automatically Assessing Lexical Sophistication: Indices, Tools, Findings, and Application.” Tesol Quarterly 44 (4): 757-86.

Laliberté, Jean-William. 2019. "Language skill acquisition in immigrant social networks: Evidence from Australia." Labour Economics 57, pp. 35-45.

Lieberson, Stanley. Language Diversity and Language Contact. Stanford University Press, Stanford, CA 94305, 1981.

Lleras-Muney, Adriana, and Allison Shertzer. 2015. "Did the Americanization Movement Succeed? An Evaluation of the Effect of English-Only and Compulsory Schooling Laws on Immigrants." American Economic Journal: Economic Policy 7 (3): 258-90.

Lopez, Mark Hugo, Jeffrey S. Passel and D’Vera Cohn. 2021. “Key Facts about the Changing U.S. Unauthorized Immigrant Population." Pew Research Center. Retrieved from: https://www.pewresearch.org/fact-tank/2021/04/13/key-facts-about-the-changing-u-sunauthorized-immigrant-population/

Luthra, Rene, Thomas Soehl, and Roger Waldinger. 2018. "Reconceptualizing Context: A Multilevel Model of the Context of Reception and Second Generation Educational Attainment." International Migration Review 52(3): 898-928.

Luthra, Rene, Thomas Soehl, and Roger Waldinger. 2018. Origins and Destinations: The Making of the Second Generation. Russel Sage Foundation.

Massey, Douglas S., Rafael Alarcón, Jorge Durand, and Humberto González. 1990 Return to Aztlan: The Social Process of International Migration from Western Mexico. Vol. 1. Univ of California Press.

Menjivar, Cecilia. 2000. Fragmented Ties: Salvadoran Immigrant Networks in America. University of California Press.

Monroe, Burt L., Michael P. Colaresi, and Kevin M. Quinn. 2008. "Fightin'words: Lexical feature selection and evaluation for identifying the content of political conflict." Political Analysis, 16(4), 372-403.

Morawska, Ewa. 2004. For Bread with Butter: Life-Worlds of East Central Europeans in Johnstown, Pennsylvania 1890-1940. Cambridge University Press.

Morgan, S. Philip, Susan C. Watkins, and Doug Ewbank. 1993. "Generating Americans." In After Ellis Island, edited by S. C. Watkins. New York: Russell Sage Foundation.

Moyer, Alene. 1999. "Ultimate Attainment in L2 Phonology: The Critical Factors of Age, Motivation, and Instruction." Studies in Second Language Acquisition, 21(1), 81-108.

Munro, Murray J., and Tracey M. Derwing. 1998. "The Effects of Speaking Rate on Listener Evaluations of Native and Foreign-Accented Speech." Language Learning 48 (2): 15982.

Ochs, Elinor. n.d. “Transcription as Theory.” Developmental Pragmatics 10 (1): 43-72. 
Pagnini, Deanna and S. Philip Morgan. 1990. "Ethnic Intermarriage at the Turn of the Century." American Journal of Sociology 95: 405-432.

Patkowski, Mark. 1990. "Age and accent in a second language: A reply to James Emil Flege. Applied Linguistics." 11(1): 73-89.

Perlmann, Joel and Roger Waldinger. 1997. "Second Generation Decline? Children of Immigrants, Past and Present - A Reconsideration.” International Migration Review 31(4): 893-922.

Piore, Michael J. 1980. Birds of Passage. Cambridge University Press).

Portes, Alejandro, and Lingxin Hao. 1998. "E Pluribus Unum: Bilingualism and Loss of Language in the Second Generation." Sociology of Education, 269-94.

Portes, Alejandro and Ruben Rumbaut. 2001. Legacies: The Story of the Immigrant Second Generation. University of California Press.

Price, Joseph, Kasey Buckles, Jacob Van Leeuwen, and Isaac Riley. 2019. "Combining Family History and Machine Learning to Link Historical Records." NBER Working Paper 26227.

Riggenbach, Heidi. 1991. "Toward an Understanding of Fluency: A Microanalysis of Nonnative Speaker Conversations.” Discourse Processes 14 (4): 423-41.

Ruiz, Isabel, and Carlos Vargas-Silva. 2018. "Differences in Labour Market Outcomes between Natives, Refugees and Other Migrants in the UK." Journal of Economic Geography 18 (4): 855-85.

Sassler, Sharon. 2006. "School Participation of Immigrant Youths in the Early $20^{\text {th }}$ Century: Integration or Segmented Assimilation?" Sociology of Education 79(1): 1-24.

Shin, Hyoung-jin, and Richard Alba. 2009. "The Economic Value of Bilingualism for Asians and Hispanics 1.” In Sociological Forum, 24:254-75. Wiley Online Library.

Skehan, Peter. 1998. "Task-Based Instruction.” Annual Review of Applied Linguistics 18: 26886.

Spörlein, C. and Schlueter, E., 2021. "Ethnic Insults in YouTube comments: Social Contagion and Selection Effects during the German 'Refugee Crisis"'. European Sociological Review, 37(3), pp.411-428.

Tran, Van C., and Francisco Lara-Garcia. 2020 "A New Beginning: Early Refugee Integration in the United States." RSF: The Russell Sage Foundation Journal of the Social Sciences 6(3): 117-149.

UNHCR. 2021. "What is a Refugee: A Person Forced to Flee Their Country Because of Violence or Persecution.” Retrieved from https://www.unrefugees.org/refugee-facts/whatis-a-refugee/ 
UNHCR. 2022. "More than 100 Million People are Forcibly Displaced." Retrieved from https://www.unhcr.org/refugee-statistics/insights/explainers/100-million-forciblydisplaced.html"

van Tubergen, Frank. 2010. "Determinants of Second Language Proficiency among Refugees in the Netherlands.” Social Forces 89(2): 515-534.

Van Tubergen, Frank. and Matthijs Kalmijn. 2005. Destination-language proficiency in cross national perspective: A study of immigrant groups in nine western countries. American Journal of Sociology, 110(5), pp.1412-1457.

Ward, Zachary. 2020. "The Low Return to English Fluency during the Age of Mass Migration." European Review of Economic History 24 (2): 219-42.

Waters, Mary, and Marisa Pineau. 2016. The Integration of Immigrants into American Society. National Academies Press.

Zagheni, E., Weber, I. and Gummadi, K., (2017). Leveraging Facebook's advertising platform to monitor stocks of migrants. Population and Development Review, pp.721-734.

Zipperstein, Steven J. 2013. Imagining Russian Jewry: Memory, History, Identity. University of Washington Press.

Zolberg, Aristide R. 1988. "The Roots of American Refugee Policy." Social Research 55(4): 649-678

Zwysen, Wouter. 2019. "Different Patterns of Labor Market Integration by Migration Motivation in Europe: The Role of Host Country Human Capital." International Migration Review 53 (1): 59-89. 


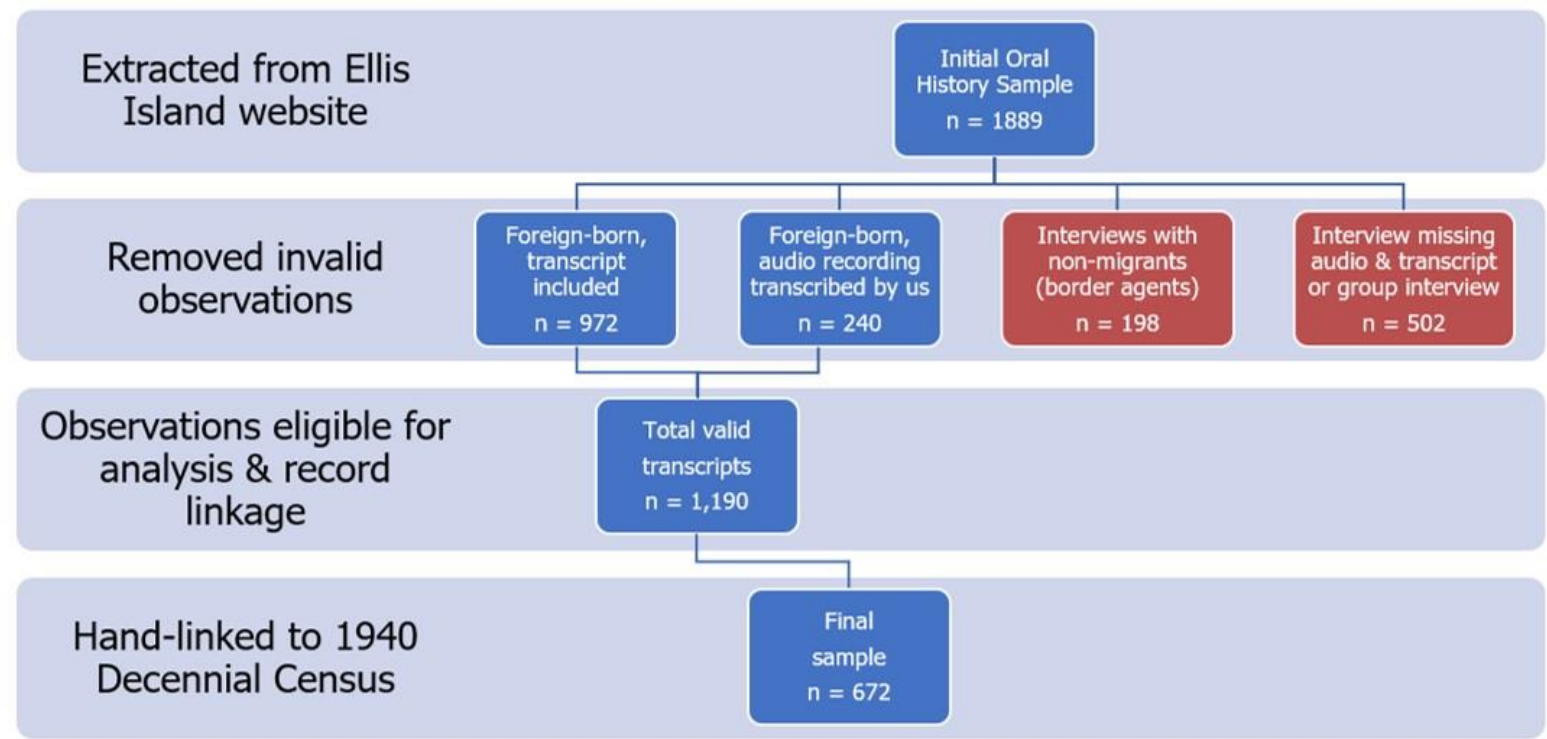

Figure 1. Sample construction flowchart. The flowchart demonstrates the construction of the samples used in the analysis of the paper. We start with a sample of 1,899 oral histories collected from the Ellis Island Foundation website. After accounting for missing or incomplete files and interviews with non-immigrants, we end up with a sample of 1,190 oral histories. We are then able to link 672 of these individuals to the 1940 census. 
A

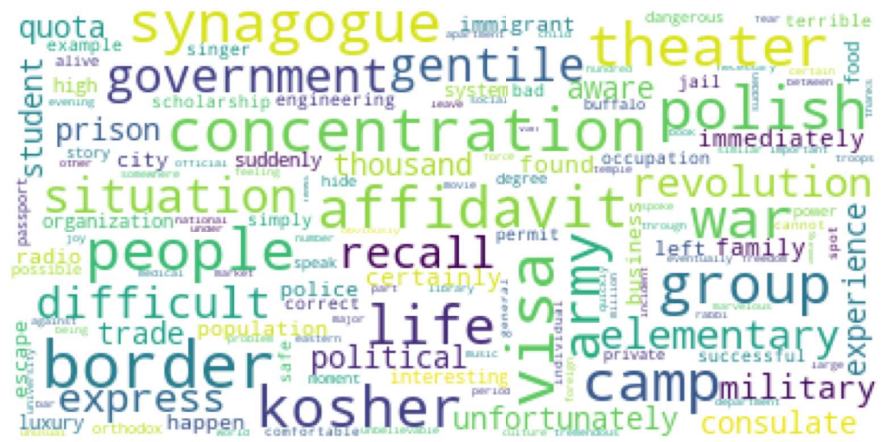

B

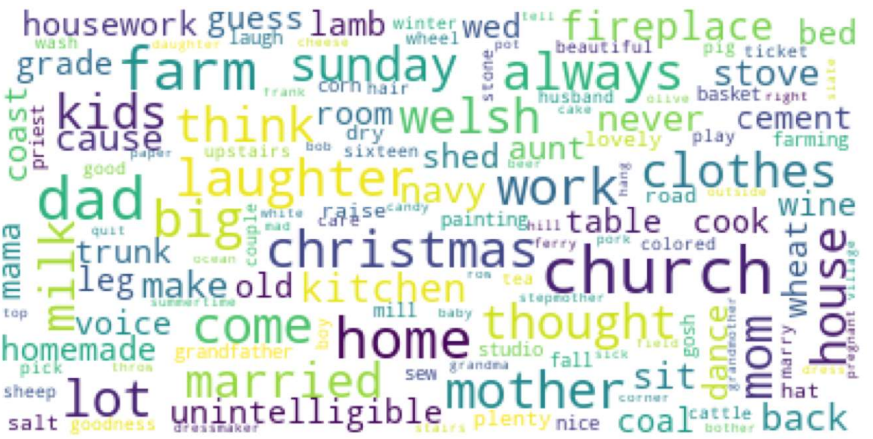

Figure 2. Interview word clouds by refugee status. A depicts a word cloud highlighting frequent words appearing in interviews with refugees or those who immigrated for mixed reasons. Refugee $=1$ indicates that an immigrant was coded as a refugee in both the first and second round of coding. Mixed reasons $=1$ indicates that an immigrant was coded as a refugee in only the first round or only the second round. Here, we combine the two into an indicator $=1$ if an immigrant was either coded as a refugee or as moving for mixed reasons. $\mathbf{B}$ depicts a word cloud highlighting words that frequently appear in economic migrant interviews. Frequency of words is calculated using a log-odds ratio. 


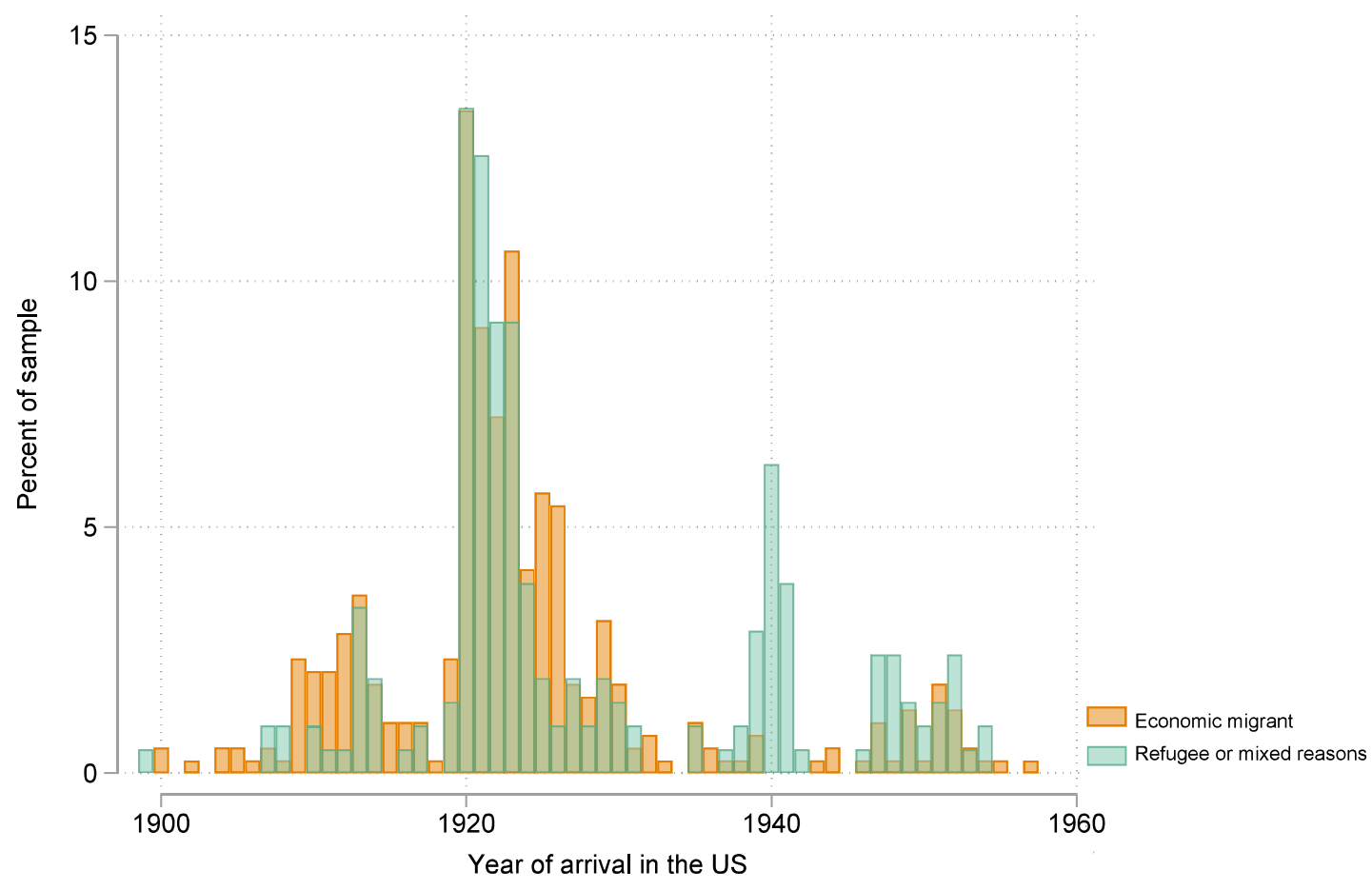

Figure 3. The distribution of immigrant arrival year by refugee status for immigrants arriving to the US after age 12. Refugee $=1$ indicates that an immigrant was coded as a refugee in both the first and second round of coding. Mixed reasons $=1$ indicates that an immigrant was coded as a refugee in only the first round or only the second round. Here, we combine the two into an indicator $=1$ if an immigrant was either coded as a refugee or as moving for mixed reasons. 


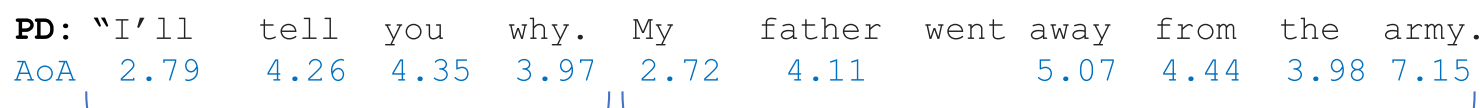

SL: 4

SL: 7

The, you know, the Russian Army with the, uh, the Japanese Army was fighting at that time. He was a soldier in the Russian Army, you know, and he didn't want to stay there, and he came over here in 1905, my father. Then after a couple, two years more, so he took my mother and three boys up, you understand, three brothers."

Mean Sentence Length: 11.61; Mean AoA: 4.62

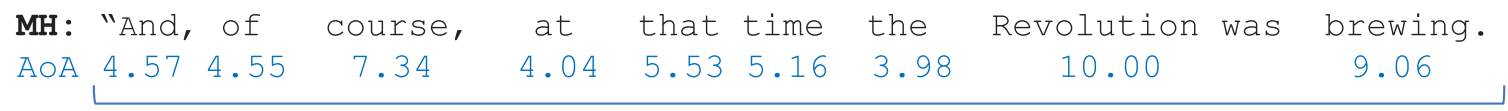

SL: 10

I was born in 1914. I think it's important that I indicate the date, March $22,1914$. And it was prior to the Russian Revolution and things were becoming very hectic. And, and all of a sudden the Revolution comes, in 1917, and, uh, we're, we're all in a state of upheaval, a terrible hunger ensured that, uh, thousands of people were just dying like flies."

Mean Sentence Length: $18.44 ;$ Mean AoA: 5.72

Figure 4. Examples of Age of Acquisition and Mean Sentence Length. This figure lists examples of Age of Acquisition (AoA) and Mean Sentence Length (MSL) from transcripts of two different migrants, Paul Deutsch (PD) and Morris Helzner $(\mathrm{MH})$. We also note that Morris Helzner had an accent closer to that of natives as compared to Paul Deutsch. Morris was assigned an accent $\mathrm{z}$-score of 0.38 while Paul had a score of -0.36 , where a more positive score indicates an accent closer to that of natives. 
A

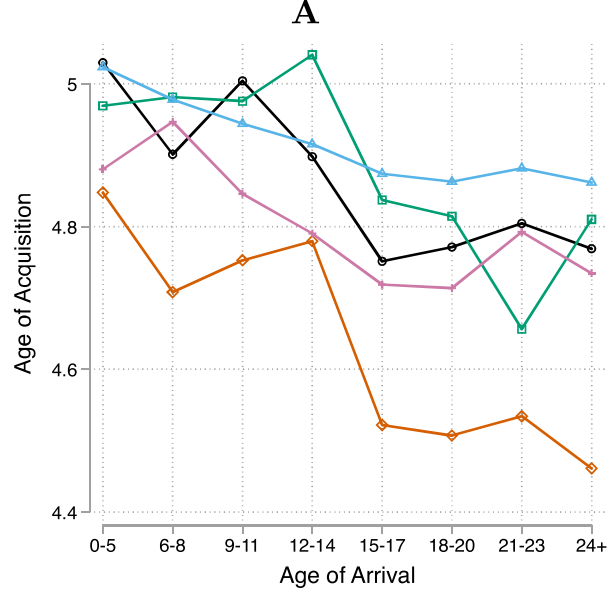

C

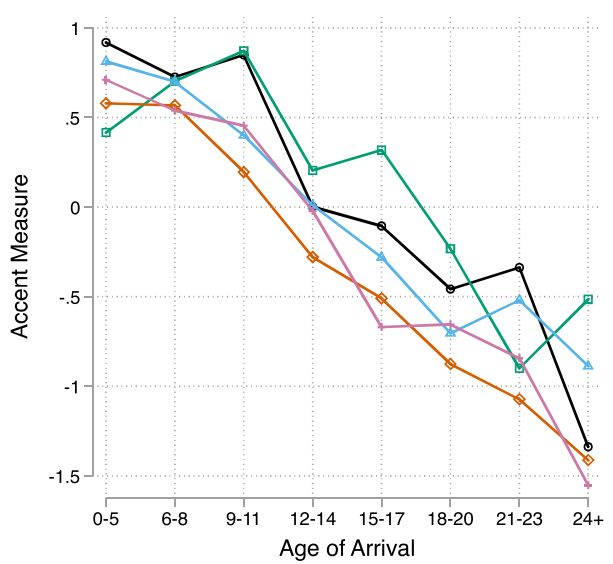

B

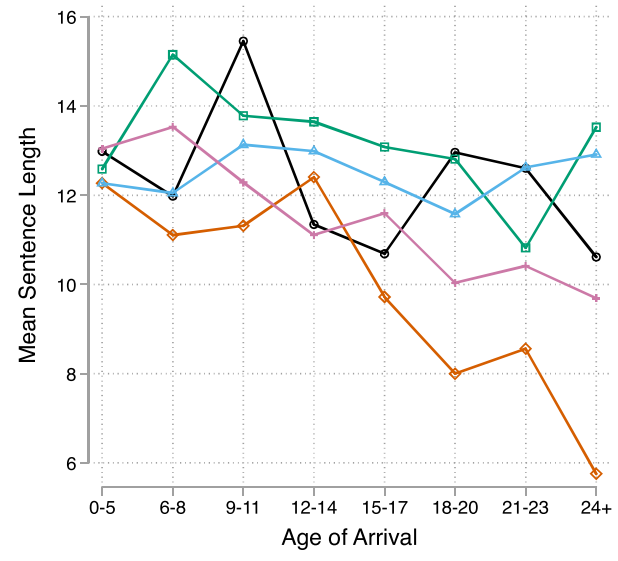

D

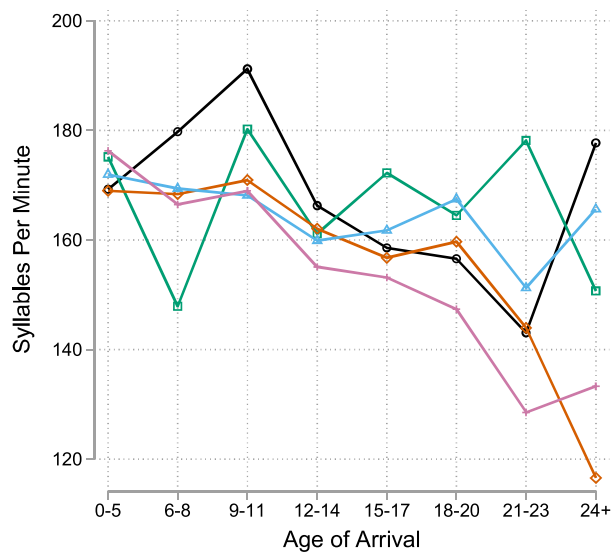

Figure 5. Mean linguistic measures by age of arrival and birthplace. Panel A plots mean Age of Acquisition (AoA) (N= 952), Panel B plots Mean Sentence Length ( $=952$ ), Panel $\mathbf{C}$ plots accent measure (where positive indicates accent closer to native) $(\mathrm{N}=809)$, and Panel $\mathbf{D}$ plots Syllables Per Minute $(\mathrm{N}=789)$ by age of arrival and birthplace. Migrants arriving after 1933 are dropped. 


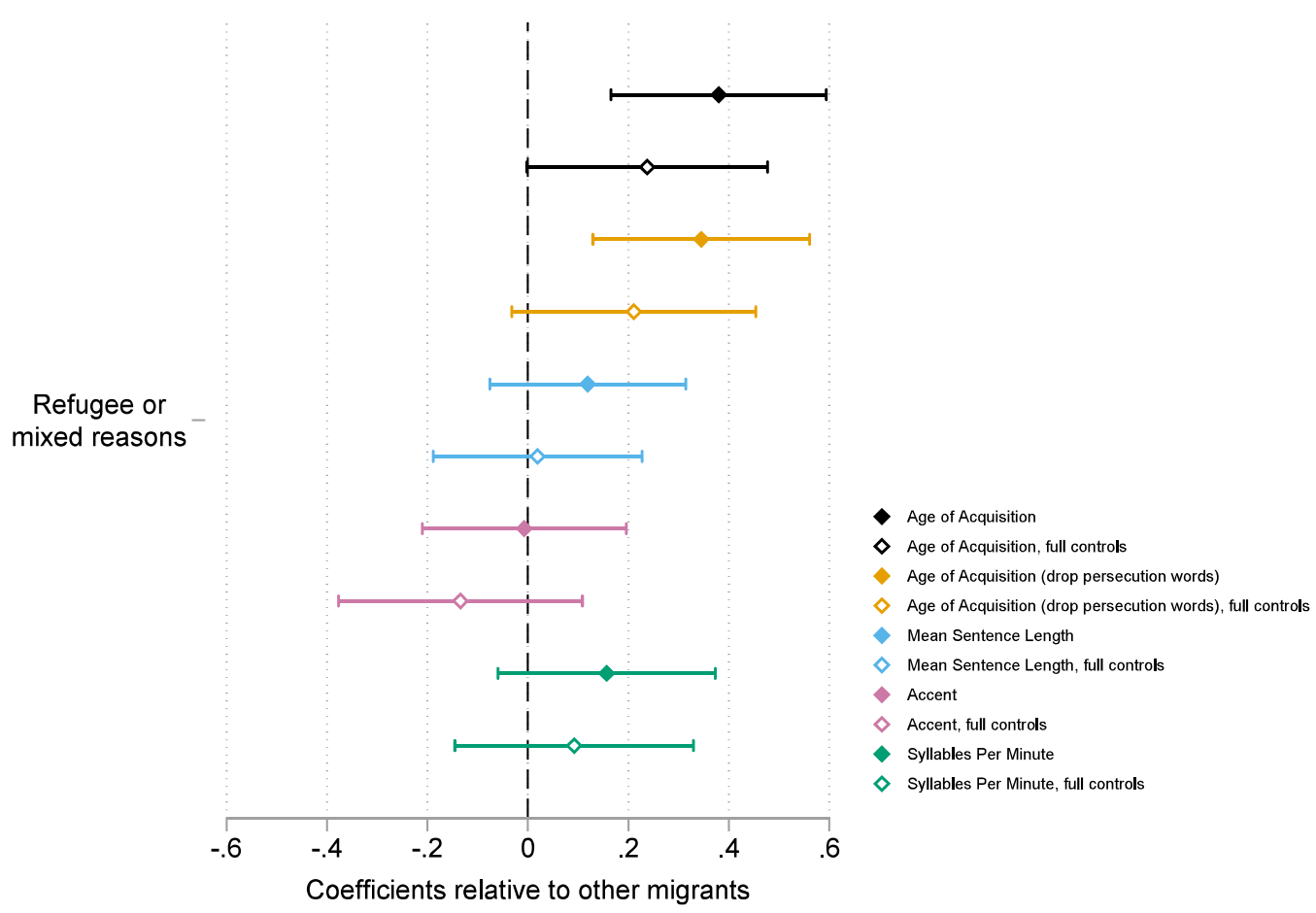

Figure 6. Association between refugee status and linguistic outcomes for immigrants arriving after age 12. The five linguistic measures are: Age of Acquisition ( $\mathrm{N}=451, \mathrm{~N}=359$ with full controls), Age of Acquisition calculated after dropping persecution related words $(\mathrm{N}=451, \mathrm{~N}=359)$, Mean Sentence Length $(\mathrm{N}=451, \mathrm{~N}=359)$, Accent $(\mathrm{N}=391, \mathrm{~N}=317)$ and Syllables Per Minute $(\mathrm{N}=381, \mathrm{~N}=309)$. Linguistic measures have been standardized to have a mean of zero and standard deviation of one. Refugee $=1$ indicates that an immigrant was coded as a refugee in both the first and second round of coding. Mixed reasons $=1$ indicates that an immigrant was coded as a refugee in only the first round or only the second round. Here, we combine the two into an indicator $=1$ if an immigrant was either coded as a refugee or as moving for mixed reasons. English speaking immigrants, those from Britain and Ireland, are not included in this sample. A more positive accent score indicates an accent closer to that of the US born. Controls for all regressions include age, age squared, arrival period, birthplace and gender. Added controls in regressions with "full controls" include father's pre-migration occupation, pre-migration urban status and religion. Significance is at the $5 \%$ level. 


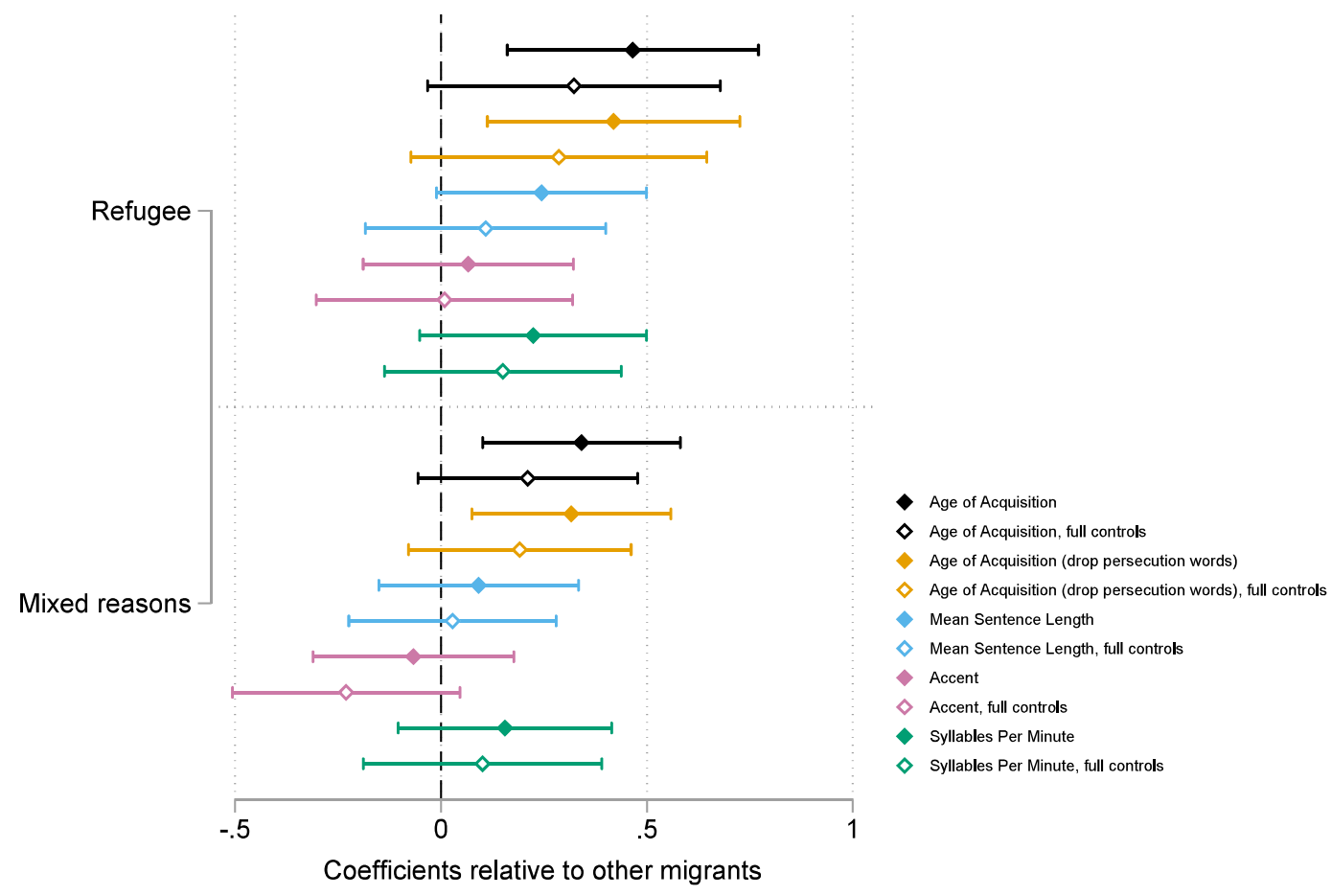

Figure 7. Association between refugee status and linguistic outcomes for immigrants arriving after age 12. We include two main explanatory variables. Refugee $=1$ indicates that an immigrant was coded as a refugee in both the first and second round of coding, i.e., both round 1 and round 2 of coding independently agreed the immigrant was refugee. Mixed reasons $=1$ indicates that an immigrant was coded as a refugee in only the first round or only the second round. Coefficients are relative to immigrants who were not coded as a refugee in either round 1 or round 2. The five linguistic measures are: Age of Acquisition ( $\mathrm{N}=444, \mathrm{~N}=350$ with full controls), Age of Acquisition calculated after dropping persecution related words $(\mathrm{N}=444, \mathrm{~N}=350)$, Mean Sentence Length $(\mathrm{N}=444, \mathrm{~N}=350)$, Accent $(\mathrm{N}=389, \mathrm{~N}=313)$ and Syllables Per Minute $(\mathrm{N}=379$, $\mathrm{N}=305)$. Linguistic measures have been standardized to have a mean of zero and standard deviation of one. English speaking immigrants, those from Britain and Ireland, are not included in this sample. A more positive accent score indicates an accent closer to that of the US born. Controls for all regressions include age, age squared, arrival period, birthplace and gender. Added controls in regressions with "full controls" include father's pre-migration occupation, pre-migration urban status and religion. Significance is at the $5 \%$ level. 


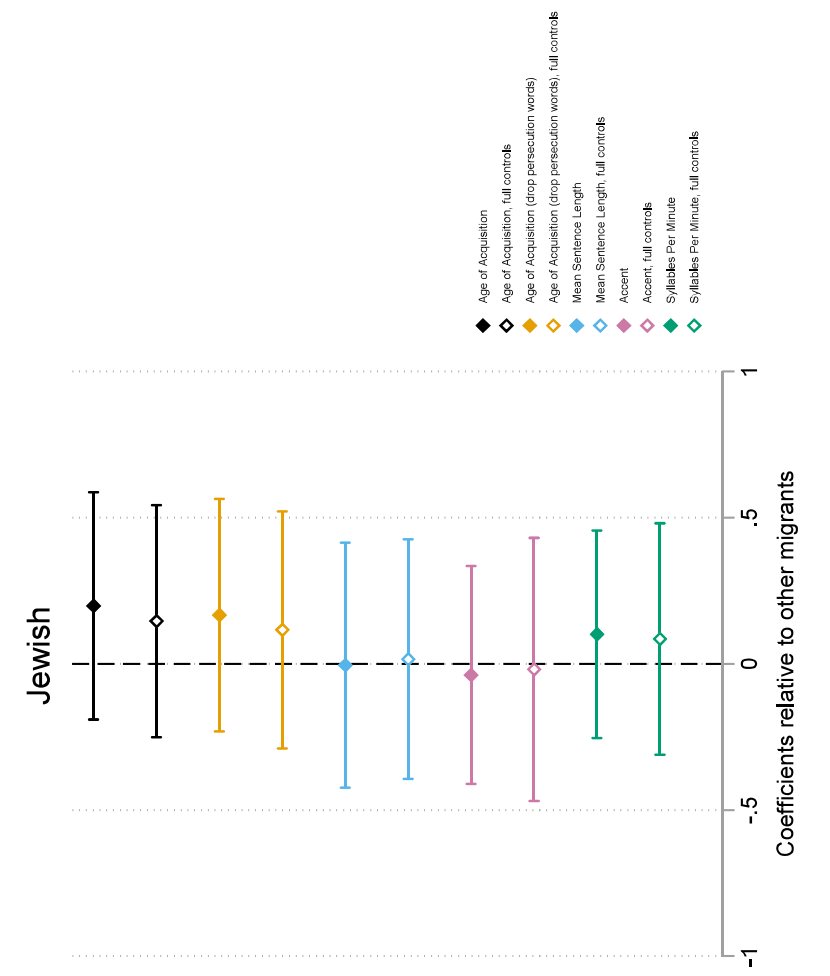

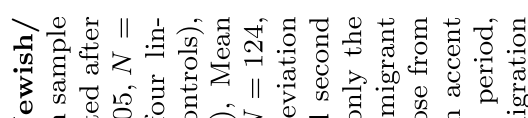

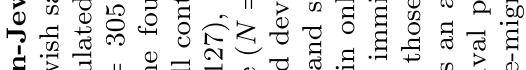

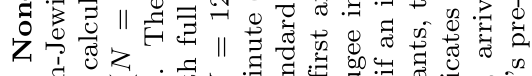

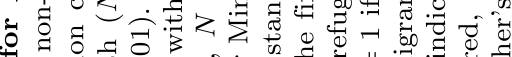

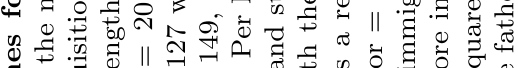

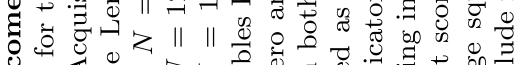

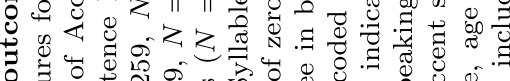

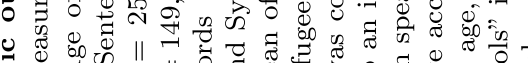

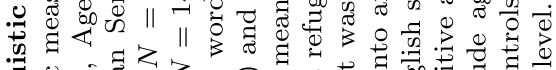

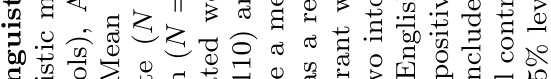

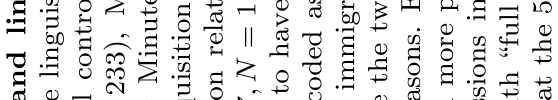

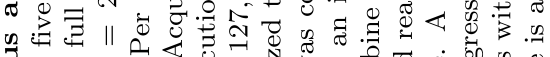

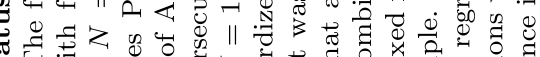

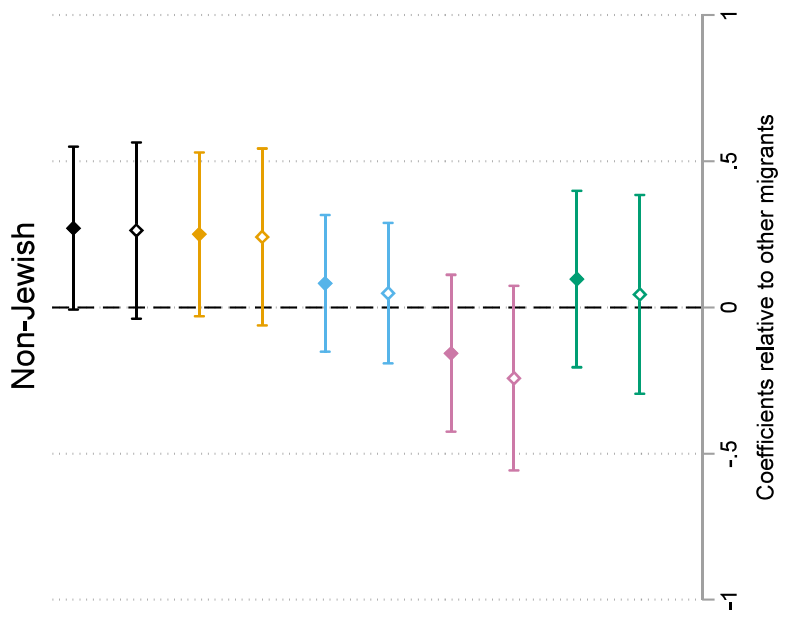
क

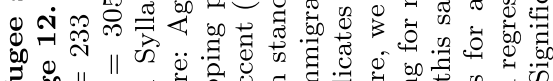

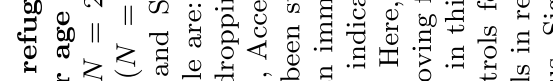
屯

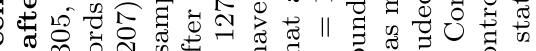

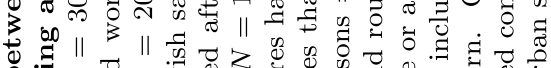

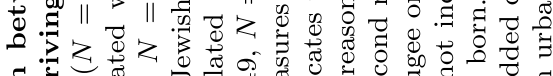

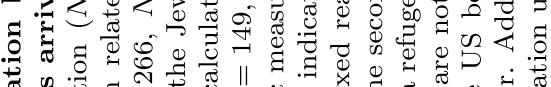

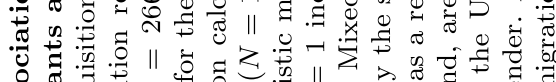

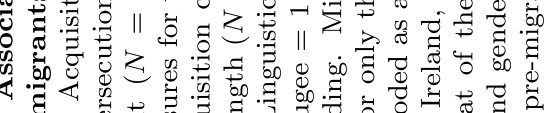

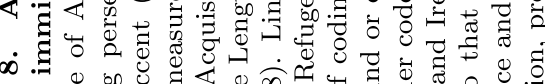

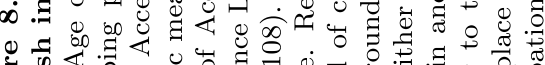

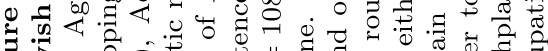

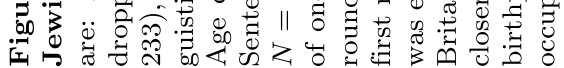

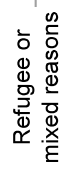




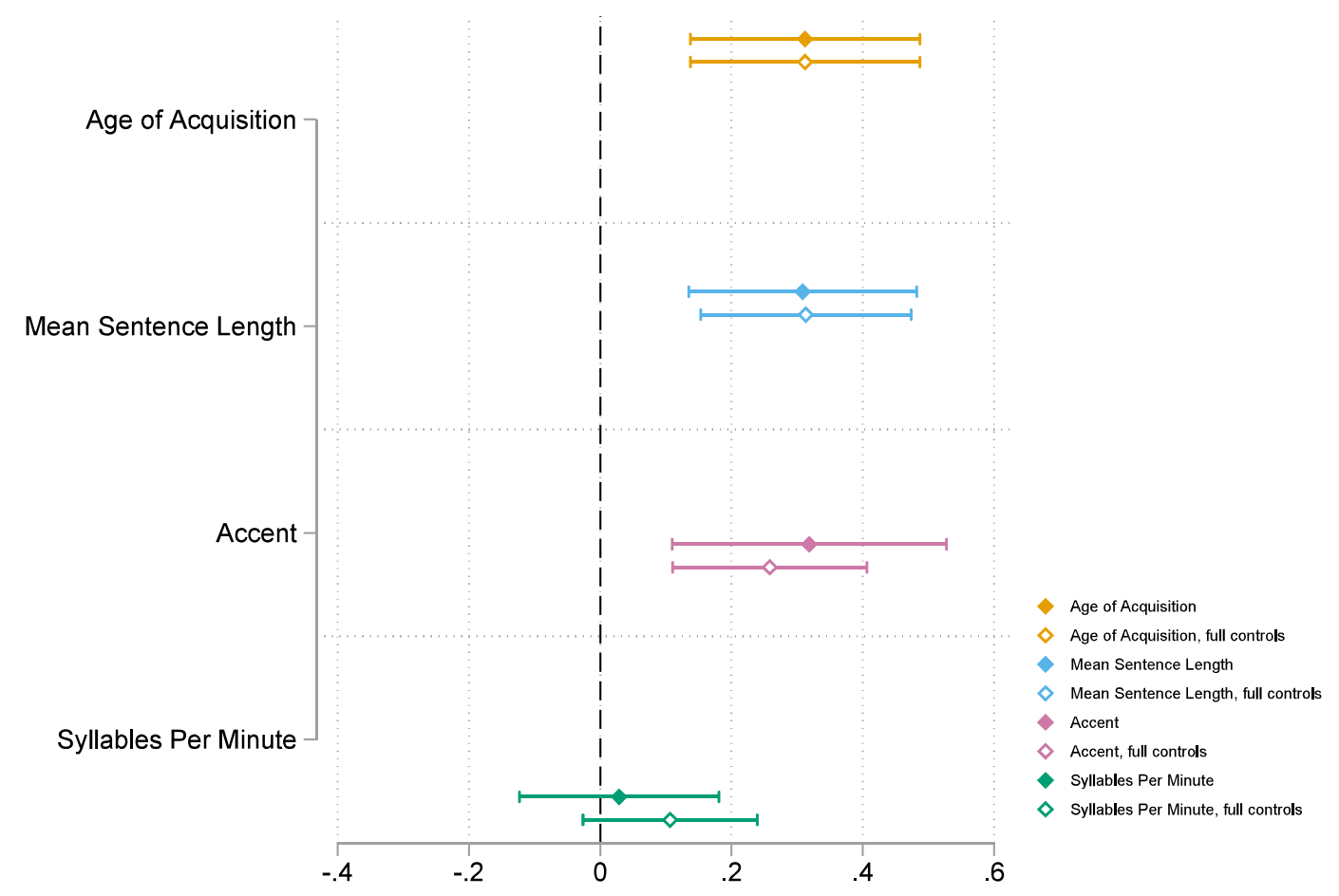

Figure 9. Regressions of logarithm of income on linguistic measures, English speakers included. This figure documents the results of four regression models where logarithm of income is regressed on (i) Age of Acquisition ( $N=277$, $N=218$ with full controls), (ii) Mean Sentence Length $(N=277, N=218)$, (iii) Accent $(N=243, N=193)$ and (iv) Syllables Per Minutes $(N=238, N=189)$. Linguistic measures have been standardized. Controls include age, age squared, arrival period, birthplace, gender and an indicator for arriving before or after the age of 12. Added controls in regressions with "full controls" include father's pre-migration occupation, pre-migration urban status and religion. Results are weighted by the propensity of being matched. English speaking immigrants, those from Britain and Ireland, are included in this sample. Significance is at the $5 \%$ level. 
Table 1. Summary of full sample, refugees and economic migrants.

\begin{tabular}{|c|c|c|c|c|c|c|}
\hline & \multicolumn{2}{|c|}{ Full } & \multicolumn{2}{|c|}{ Refugee or mixed reasons } & \multicolumn{2}{|c|}{ Economic } \\
\hline & Frequency & Percent & Frequency & Percent & Frequency & Percent \\
\hline \multicolumn{7}{|l|}{ Gender } \\
\hline Men & 528 & 44.37 & 201 & 56.78 & 327 & 39.11 \\
\hline Women & 662 & 55.63 & 153 & 43.22 & 509 & 60.89 \\
\hline $\mathrm{N}$ & 1190 & & 354 & & 836 & \\
\hline \multicolumn{7}{|l|}{ Arrived as child } \\
\hline Before age 12 & 574 & 48.24 & 141 & 39.83 & 433 & 51.79 \\
\hline After age 12 & 616 & 51.76 & 213 & 60.17 & 403 & 48.21 \\
\hline $\mathrm{N}$ & 1190 & & 354 & & 836 & \\
\hline \multicolumn{7}{|l|}{ Arrival Period } \\
\hline $1890-1914$ & 254 & 21.6 & 55 & 15.67 & 199 & 24.12 \\
\hline $1915-1923$ & 534 & 45.41 & 170 & 48.43 & 364 & 44.12 \\
\hline 1924-1933 & 241 & 20.49 & 43 & 12.25 & 198 & 24 \\
\hline 1934 onward & 147 & 12.5 & 83 & 23.65 & 64 & 7.76 \\
\hline $\mathrm{N}$ & 1176 & & 351 & & 825 & \\
\hline \multicolumn{7}{|l|}{ Country of Birth } \\
\hline Austria \& Germany & 143 & 12.02 & 56 & 15.82 & 87 & 10.41 \\
\hline Britain \& Ireland & 119 & 10 & 8 & 2.26 & 111 & 13.28 \\
\hline Italy & 206 & 17.31 & 28 & 7.91 & 178 & 21.29 \\
\hline Russia \& Poland & 236 & 19.83 & 122 & 34.46 & 114 & 13.64 \\
\hline Rest of World & 486 & 40.84 & 140 & 39.55 & 346 & 41.39 \\
\hline $\mathrm{N}$ & 1190 & & 354 & & 836 & \\
\hline \multicolumn{7}{|l|}{ Religion } \\
\hline Catholic & 302 & 32.44 & 43 & 14.24 & 259 & 41.18 \\
\hline Jewish & 326 & 35.02 & 193 & 63.91 & 133 & 21.14 \\
\hline Orthodox & 56 & 6.02 & 13 & 4.3 & 43 & 6.84 \\
\hline Protestant & 247 & 26.53 & 53 & 17.55 & 194 & 30.84 \\
\hline $\mathrm{N}$ & 931 & & 302 & & 629 & \\
\hline \multicolumn{7}{|l|}{ Father Occupation } \\
\hline Farmer & 161 & 17.61 & 27 & 9.25 & 134 & 21.54 \\
\hline Laborer & 145 & 15.86 & 35 & 11.99 & 110 & 17.68 \\
\hline Skilled & 361 & 39.5 & 111 & 38.01 & 250 & 40.19 \\
\hline White collar & 247 & 27.02 & 119 & 40.75 & 128 & 20.58 \\
\hline $\mathrm{N}$ & 914 & & 292 & & 622 & \\
\hline \multicolumn{7}{|l|}{ Urban } \\
\hline Urban & 362 & 30.42 & 141 & 39.83 & 221 & 26.44 \\
\hline Non urban & 828 & 69.58 & 213 & 60.17 & 615 & 73.56 \\
\hline $\mathrm{N}$ & 1190 & & 354 & & 836 & \\
\hline
\end{tabular}

Note: Refugee $=1$ indicates that an immigrant was coded as a refugee in both the first and second round of coding. Mixed reasons $=1$ indicates that an immigrant was coded as a refugee in only the first round or only the second round. We combine the two into an indicator $=1$ if an immigrant was either coded as a refugee or as moving for mixed reasons. The "Rest of World" category includes the rest of Europe, Asia and South America. 
Table 2. Socio-economic characteristics of linked immigrants.

\begin{tabular}{|c|c|c|c|c|c|c|}
\hline & \multicolumn{2}{|c|}{ Full } & \multicolumn{2}{|c|}{ Refugee or mixed reasons } & \multicolumn{2}{|c|}{ Economic } \\
\hline & Frequency & Percent & Frequency & Percent & Frequency & Percent \\
\hline \multicolumn{7}{|c|}{ Occupation class } \\
\hline Farmer & 6 & 1.65 & 0 & 0 & 6 & 2.36 \\
\hline Laborer & 47 & 12.95 & 8 & 7.34 & 39 & 15.35 \\
\hline Skilled & 173 & 47.66 & 49 & 44.95 & 124 & 48.82 \\
\hline White Collar & 137 & 37.74 & 52 & 47.71 & 85 & 33.46 \\
\hline$N$ & 363 & & 109 & & 254 & \\
\hline \multicolumn{7}{|l|}{ Income } \\
\hline $1-499$ & 53 & 18.47 & 17 & 22.37 & 36 & 17.06 \\
\hline $500-999$ & 83 & 28.92 & 12 & 15.79 & 71 & 33.65 \\
\hline $1000+$ & 151 & 52.61 & 47 & 61.84 & 104 & 49.29 \\
\hline$N$ & 287 & & 76 & & 211 & \\
\hline \multicolumn{7}{|c|}{ Years of schooling } \\
\hline $0-4$ & 61 & 9.41 & 18 & 10.78 & 43 & 8.94 \\
\hline $5-8$ & 299 & 46.14 & 55 & 32.93 & 244 & 50.73 \\
\hline $9-12$ & 216 & 33.33 & 67 & 40.12 & 149 & 30.98 \\
\hline 13 & 72 & 11.11 & 27 & 16.17 & 45 & 9.36 \\
\hline$N$ & 648 & & 167 & & 481 & \\
\hline
\end{tabular}

Note: This table presents socio-economic characteristics of the immigrants that were linked to the 1940 census. Income is from the incwage variable in the 1940 Census. Refugee $=1$ indicates that an immigrant was coded as a refugee in both the first and second round of coding. Mixed reasons $=1$ indicates that an immigrant was coded as a refugee in only the first round or only the second round. Here, we combine the two into an indicator $=1$ if an immigrant was either coded as a refugee or as moving for mixed reasons. 
Table 3. Association between refugee status and English fluency in the New Immigrant Survey

\begin{tabular}{|c|c|c|c|c|}
\hline & (1) & (2) & (3) & (4) \\
\hline \multicolumn{5}{|c|}{ Panel A: Outcome: Speaks any English } \\
\hline Refugee & $\begin{array}{c}0.0168 \\
(0.031)\end{array}$ & $\begin{array}{c}0.0793^{* *} \\
(0.032)\end{array}$ & $\begin{array}{c}0.0797^{* *} \\
(0.032)\end{array}$ & $\begin{array}{c}0.0714^{*} \\
(0.037)\end{array}$ \\
\hline Recent English class & & & $\begin{array}{c}0.0691^{* * *} \\
(0.015)\end{array}$ & $\begin{array}{l}0.0489^{*} \\
(0.028)\end{array}$ \\
\hline Pre-US English class & & & $\begin{array}{c}0.103^{* * *} \\
(0.013)\end{array}$ & $\begin{array}{c}0.0491^{* *} \\
(0.024)\end{array}$ \\
\hline Adjusted $\mathrm{R}^{2}$ & 0.351 & 0.416 & 0.433 & 0.299 \\
\hline \multicolumn{5}{|c|}{ Panel B: Outcome: Speaks English Well } \\
\hline Refugee & $\begin{array}{c}-0.108^{* *} \\
(0.045)\end{array}$ & $\begin{array}{c}-0.0465 \\
(0.042)\end{array}$ & $\begin{array}{c}-0.0333 \\
(0.042)\end{array}$ & $\begin{array}{c}-0.0284 \\
(0.053)\end{array}$ \\
\hline Recent English class & & & $\begin{array}{c}-0.151^{* * *} \\
(0.018)\end{array}$ & $\begin{array}{c}-0.122^{* * *} \\
(0.042)\end{array}$ \\
\hline Pre-US English class & & & $\begin{array}{c}0.156^{* * *} \\
(0.018) \\
\end{array}$ & $\begin{array}{c}0.120^{* * *} \\
(0.038)\end{array}$ \\
\hline Add'l Control & No & Yes & Yes & Yes \\
\hline Sample Type & Full & Full & Full & In US $\geq 2$ yrs \\
\hline Adjusted $\mathrm{R}^{2}$ & 0.347 & 0.391 & 0.420 & 0.379 \\
\hline No. of Obs. & 2938 & 2938 & 2938 & 654 \\
\hline
\end{tabular}

Note: All regression specifications include fixed effects for departure timing and country of origin, as well as controls for age, age squared, and gender.

Additional Controls includes years of schooling prior to immigration, rural/urban, and religion. Specifications 1-3 use the full sample, where as specification 4 includes only immigrants who have been in the US for at least 2 years. Refugee $=1$ for immigrants with Refugee or Asylee visa status. Recent English class is defined as a current English class or one taken within the past year. Standard errors in parentheses

$* p<0.1, \quad * * p<0.05, \quad * * * p<0.01$ 


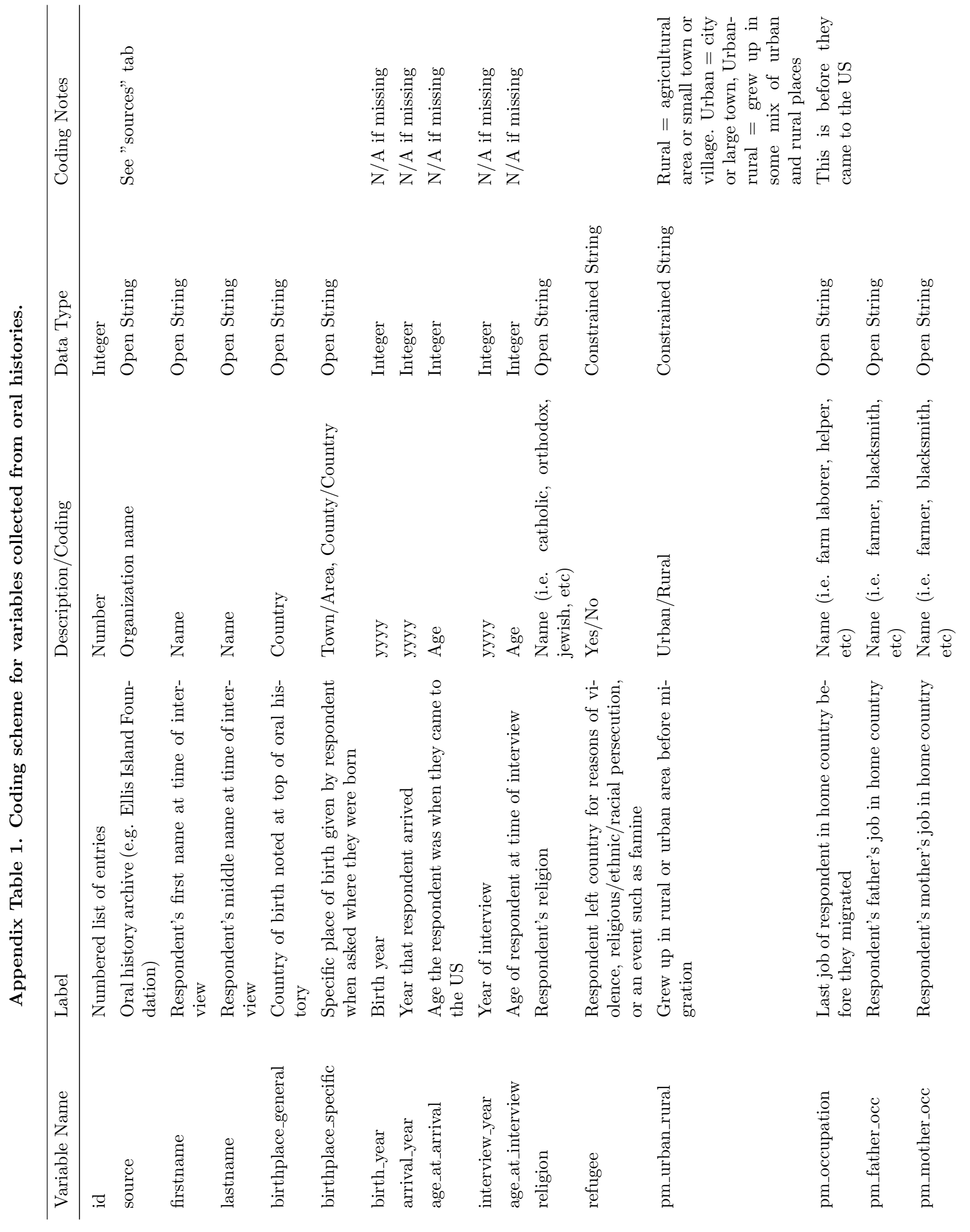




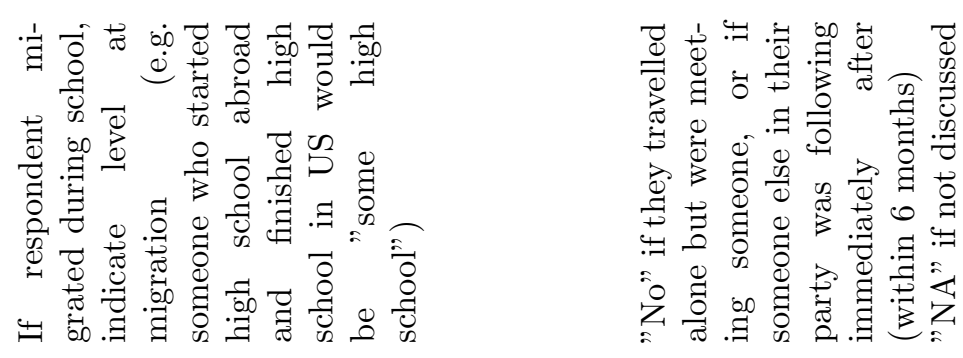

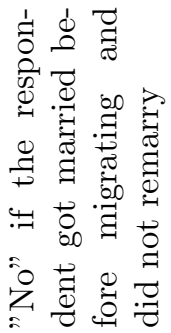
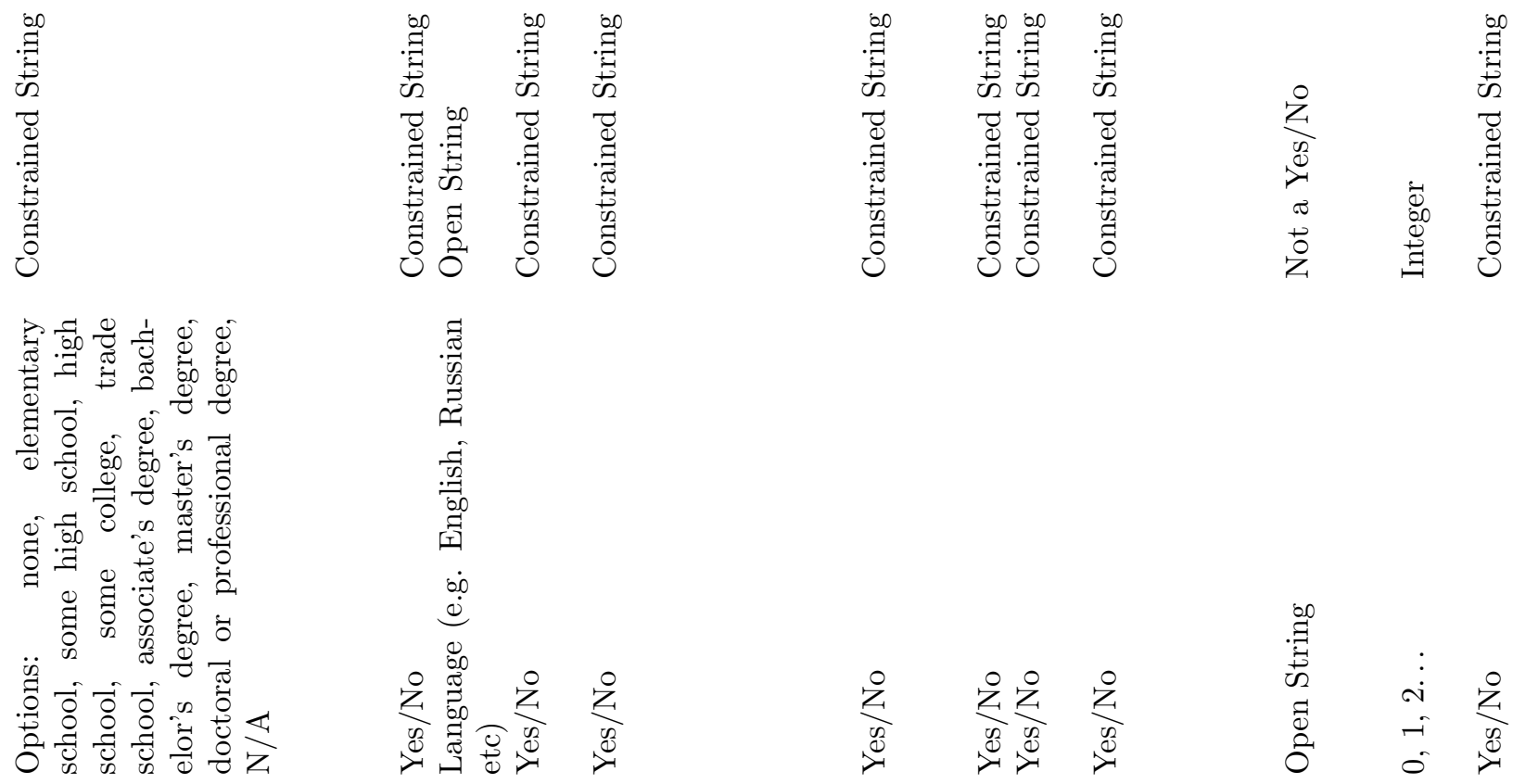

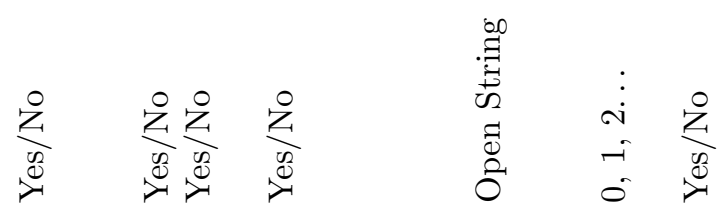
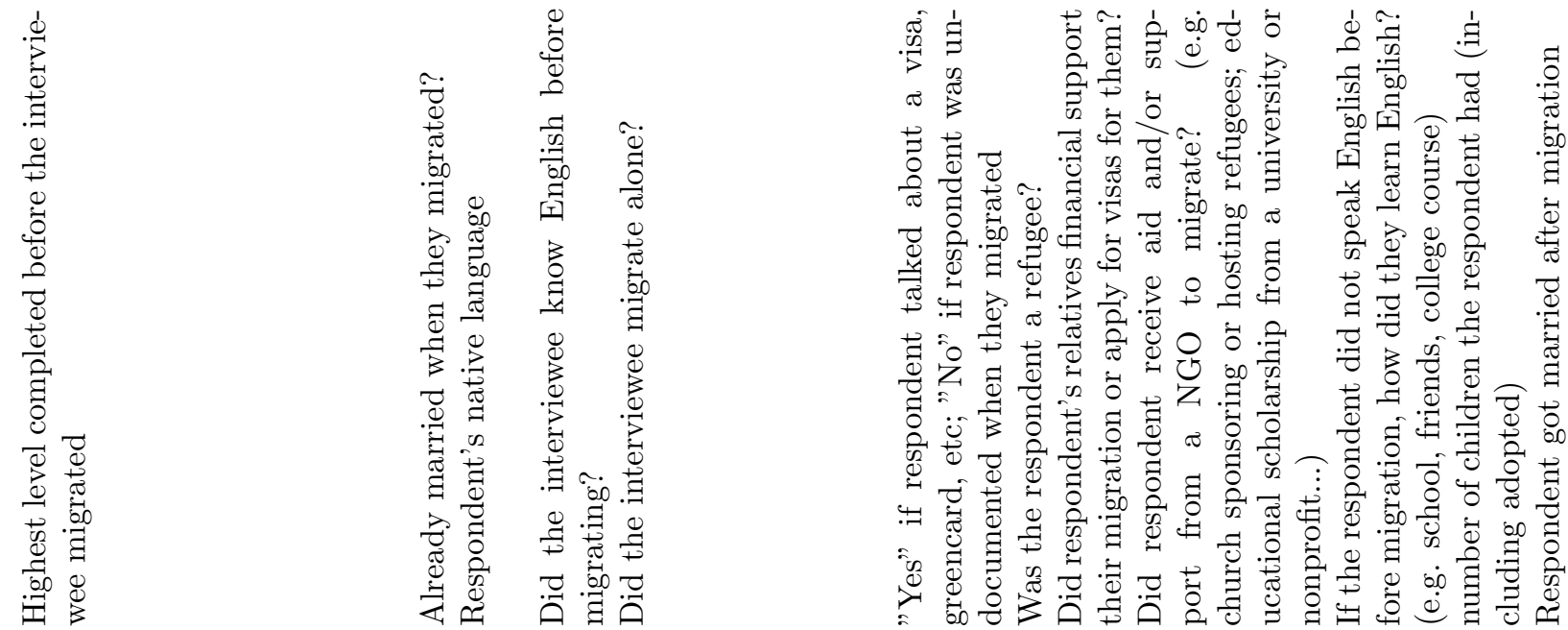

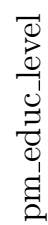
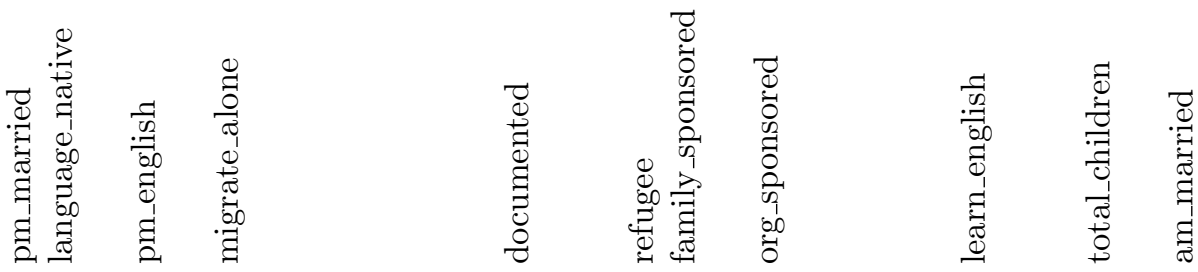


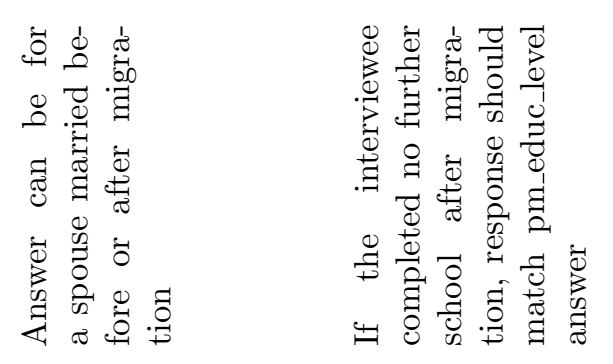

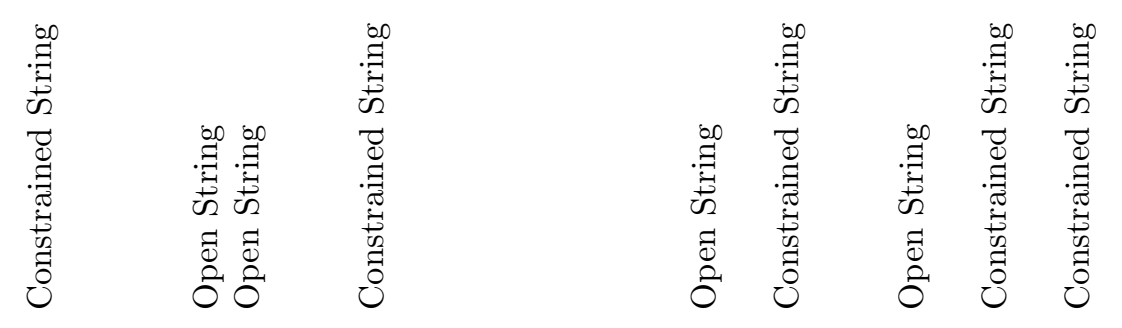

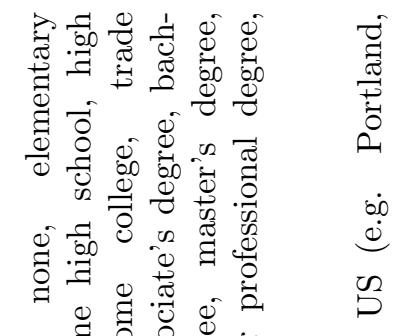

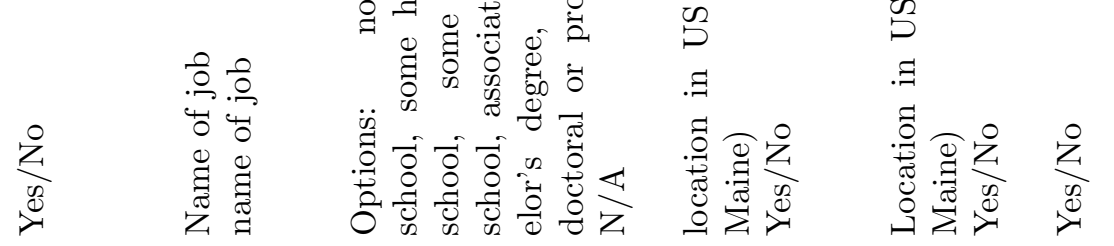
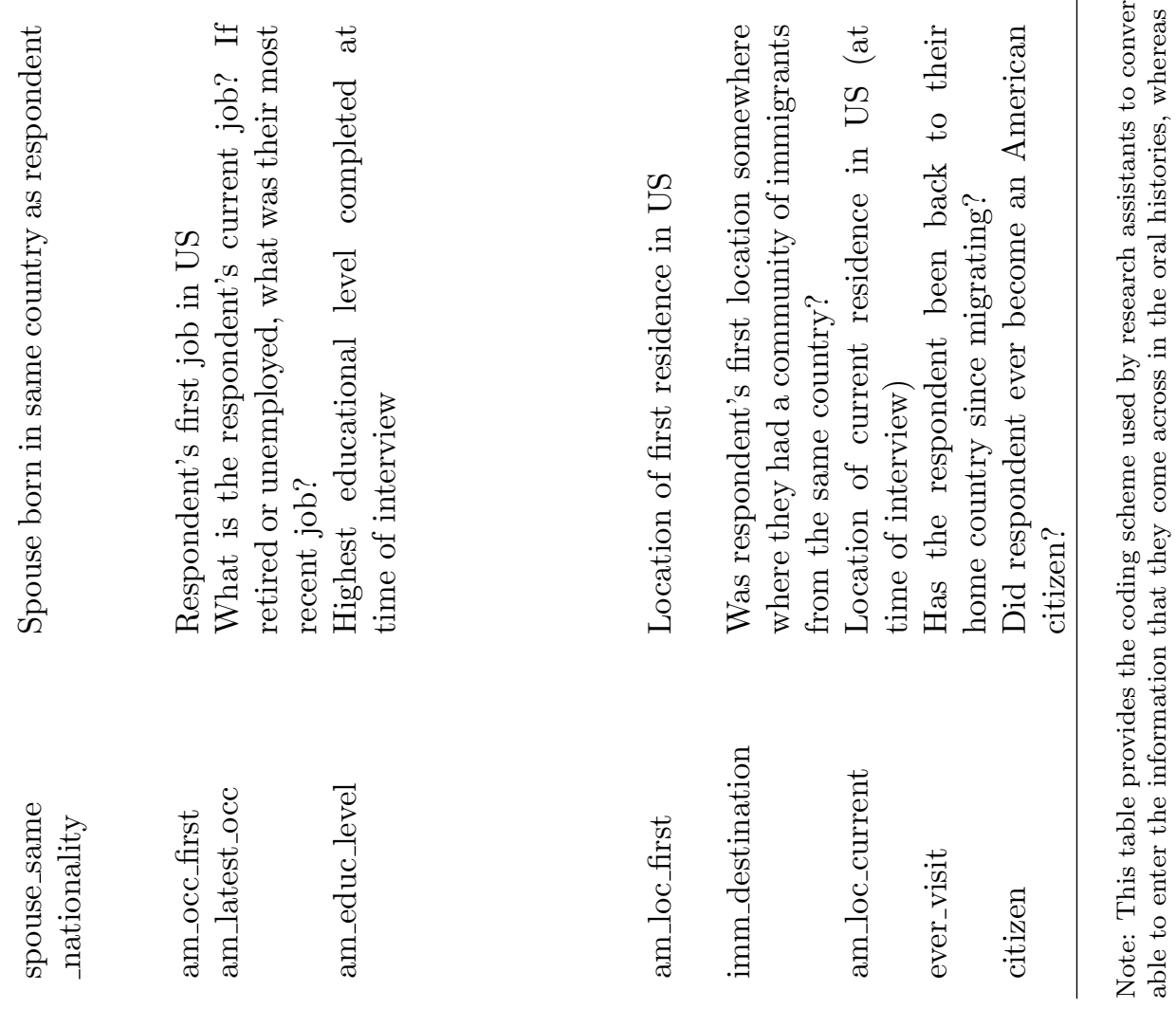
Appendix Table 2. Summary statistics of measures of linguistic ability.

\begin{tabular}{llllll}
\hline & N & Mean & Std Dev & Min & Max \\
\hline Age of Acquisition & 1100 & 4.86 & 0.33 & 4 & 6 \\
Mean Sentence Length & 1100 & 12.20 & 4.54 & 2 & 42 \\
Accent & 915 & 0 & 1 & -4 & 3 \\
Syllables Per Minute & 884 & 163.76 & 39.47 & 53 & 274 \\
\hline
\end{tabular}

Note: This table shows the summary statistics of the four measures of linguistic ability: Age of Acquisition (AoA), Mean Sentence Length (MSL), Accent and Syllables Per Minute (SPM).

Appendix Table 3. Correlation between measures of linguistic ability.

\begin{tabular}{|c|c|c|c|c|c|c|c|}
\hline & AoA & MSL & Accent & Years of Schooling & Arrival Age & Income & Syllables Per Minute \\
\hline Mean Sentence Length & 0.3812 & 1.0000 & & & & & \\
\hline Years of Schooling & 0.5394 & 0.2006 & 0.3202 & 1.0000 & & & \\
\hline Arrival age & -0.1551 & -0.1381 & -0.5214 & -0.2068 & 1.0000 & & \\
\hline Income & 0.2431 & 0.1371 & 0.0355 & 0.2389 & 0.0548 & 1.0000 & \\
\hline
\end{tabular}

Note: This table depicts correlation between the four measures of linguistic ability: Age of Acquisition (AoA), Mean Sentence Length (MSL), Accent and Syllables Per Minute (SPM) and other characteristics of migrants from our data such as years of schooling, arrival age and income. $\mathrm{N}=438$. 
Appendix Table 4. Representativeness of Linked Sample.

\begin{tabular}{|c|c|c|c|}
\hline & $\begin{array}{c}(1) \\
\text { mean non-linked }\end{array}$ & $\begin{array}{c}(2) \\
\text { mean linked }\end{array}$ & $\begin{array}{c}(3) \\
\text { difference }\end{array}$ \\
\hline Year of Arrival & $\begin{array}{c}1925 \\
(12.608)\end{array}$ & $\begin{array}{c}1920 \\
(7.373)\end{array}$ & $\begin{array}{c}-5.651^{* * *} \\
(0.587)\end{array}$ \\
\hline Arrival Age & $\begin{array}{l}14.883 \\
(8.824)\end{array}$ & $\begin{array}{l}12.429 \\
(6.080)\end{array}$ & $\begin{array}{c}-2.454^{* * * *} \\
(0.437)\end{array}$ \\
\hline Refugee or mixed reasons & $\begin{array}{c}0.593 \\
(0.471)\end{array}$ & $\begin{array}{c}0.478 \\
(0.430)\end{array}$ & $\begin{array}{c}-0.115^{* * *} \\
(0.027)\end{array}$ \\
\hline Urban & $\begin{array}{c}0.339 \\
(0.474)\end{array}$ & $\begin{array}{c}0.302 \\
(0.459)\end{array}$ & $\begin{array}{r}-0.0366 \\
(0.028)\end{array}$ \\
\hline \multicolumn{4}{|l|}{ Father Occupation } \\
\hline White Collar & 0.216 & 0.201 & $\begin{array}{c}-0.0153 \\
(0.024)\end{array}$ \\
\hline Farmer & 0.124 & 0.144 & $\begin{array}{l}0.0208 \\
(0.020)\end{array}$ \\
\hline Laborer & 0.118 & 0.125 & $\begin{array}{c}0.00724 \\
(0.019)\end{array}$ \\
\hline Skilled & 0.293 & 0.311 & $\begin{array}{l}0.0176 \\
(0.027)\end{array}$ \\
\hline \multicolumn{4}{|l|}{ Birthplace } \\
\hline Austria \& Germany & 0.149 & 0.098 & $\begin{array}{c}-0.0504^{* * *} \\
(0.019)\end{array}$ \\
\hline Britain \& Ireland & 0.098 & 0.101 & $\begin{array}{c}0.00273 \\
(0.018)\end{array}$ \\
\hline Italy & 0.148 & 0.192 & $\begin{array}{r}0.0433^{*} \\
(0.022)\end{array}$ \\
\hline Russia \& Poland & 0.187 & 0.206 & $\begin{array}{l}0.0196 \\
(0.023)\end{array}$ \\
\hline Rest of world & 0.416 & 0.402 & $\begin{array}{c}-0.0152 \\
(0.029)\end{array}$ \\
\hline \multicolumn{4}{|l|}{ Religion } \\
\hline Catholic & 0.212 & 0.285 & $\begin{array}{c}0.0734^{* * *} \\
(0.025)\end{array}$ \\
\hline Jewish & 0.289 & 0.262 & $\begin{array}{r}-0.0277 \\
(0.026)\end{array}$ \\
\hline Orthodox & 0.048 & 0.046 & $\begin{array}{c}-0.00213 \\
(0.012)\end{array}$ \\
\hline Protestant & 0.208 & 0.207 & $\begin{array}{c}-0.00165 \\
(0.024)\end{array}$ \\
\hline $\mathbf{N}$ & 518 & 672 & \\
\hline
\end{tabular}

Note: This table depicts the differences between linked and non-linked sample on a variety of immigrant characteristics from data. Column 1 reports the mean of these characteristics for non-linked sample, column 2 means for linked sample and column 3 is a difference between the two samples for the particular characteristic. Refugee $=1$ indicates that an immigrant was coded as a refugee in both the first and second round of coding. Mixed reasons $=1$ indicates that an immigrant was coded as a refugee in only the first round or only the second round. Here, we combine the two into an indicator $=1$ if an immigrant was either coded as a refugee or as moving for mixed reasons. 
Appendix Table 5. Summary of non-refugee and refugees in the National Immigrant Survey

\begin{tabular}{|c|c|c|c|c|}
\hline & \multicolumn{2}{|c|}{ Non-refugee } & \multicolumn{2}{|c|}{ Refugee } \\
\hline & Observations & Mean & Observations & Mean \\
\hline Speaks English & 2,994 & $\begin{array}{l}.74 \\
(.44)\end{array}$ & 169 & $\begin{array}{c}.85 \\
(.36)\end{array}$ \\
\hline Speaks English well & 2,994 & $\begin{array}{l}.39 \\
(.49)\end{array}$ & 169 & $\begin{array}{l}.33 \\
(.47)\end{array}$ \\
\hline English class, current or within the last year & 2,871 & $\begin{array}{l}.28 \\
(.45)\end{array}$ & 169 & $\begin{array}{l}.33 \\
(.47)\end{array}$ \\
\hline English class before arrival in US & 2,830 & $\begin{array}{l}.34 \\
(.47)\end{array}$ & 168 & $\begin{array}{l}.26 \\
(.44)\end{array}$ \\
\hline Age & 3,148 & $\begin{array}{c}40.36 \\
(14.75)\end{array}$ & 171 & $\begin{array}{c}39.93 \\
(14.62)\end{array}$ \\
\hline Female & 3,157 & $\begin{array}{c}.54 \\
(.50)\end{array}$ & 171 & $\begin{array}{c}.51 \\
(.50)\end{array}$ \\
\hline Years of schooling & 3,148 & $\begin{array}{l}12.10 \\
(4.72)\end{array}$ & 171 & $\begin{array}{l}11.37 \\
(4.11)\end{array}$ \\
\hline Rural & 3,151 & $\begin{array}{l}.42 \\
(.49)\end{array}$ & 171 & $\begin{array}{l}.41 \\
(.49)\end{array}$ \\
\hline Catholic & 3,157 & $\begin{array}{l}.32 \\
(.47)\end{array}$ & 171 & $\begin{array}{l}.12 \\
(.33)\end{array}$ \\
\hline Christian Orthodox & 3,157 & $\begin{array}{l}.11 \\
(.31)\end{array}$ & 171 & $\begin{array}{l}.18 \\
(.38)\end{array}$ \\
\hline Protestant & 3,157 & $\begin{array}{l}.15 \\
(.35)\end{array}$ & 171 & $\begin{array}{c}.26 \\
(.44)\end{array}$ \\
\hline Muslim & 3,157 & $\begin{array}{l}.11 \\
(.32)\end{array}$ & 171 & $\begin{array}{l}.12 \\
(.33)\end{array}$ \\
\hline Other Religion & 3,157 & $\begin{array}{l}.14 \\
(.35)\end{array}$ & 171 & $\begin{array}{l}.17 \\
(.38)\end{array}$ \\
\hline No Religion or declined to answer & 3,157 & $\begin{array}{l}.12 \\
(.33)\end{array}$ & 171 & $\begin{array}{l}.15 \\
(.35)\end{array}$ \\
\hline Year of departure & 3,125 & $\begin{array}{c}2000 \\
(6.73)\end{array}$ & 168 & $\begin{array}{c}1997 \\
(5.34)\end{array}$ \\
\hline Europe and Central Asia & 3,157 & $\begin{array}{l}.10 \\
(.30)\end{array}$ & 171 & $\begin{array}{l}.26 \\
(.44)\end{array}$ \\
\hline Russia, Ukraine and Poland & 3,157 & $\begin{array}{l}.03 \\
(.18)\end{array}$ & 171 & $\begin{array}{l}.36 \\
(.48)\end{array}$ \\
\hline Middle East and North/Sub-Saharan Africa & 3,157 & $\begin{array}{l}.16 \\
(.37)\end{array}$ & 171 & $\begin{array}{l}.16 \\
(.37)\end{array}$ \\
\hline Rest of World & 3,157 & $\begin{array}{c}.71 \\
(.46)\end{array}$ & 171 & $\begin{array}{c}.22 \\
(.41)\end{array}$ \\
\hline $\mathrm{N}$ & 3,157 & & 171 & \\
\hline
\end{tabular}

Note: This table presents the characteristics of the 2003 cohort of surveyed immigrants in NIS, split by non-refugee and refugee status. This cohort is a random sample of adults receiving legal permanent residence between May and November of 2003. Refugee $=1$ for immigrants with Refugee or Asylee visa status. The standard deviation of each variable is in parentheses. 
Appendix Table 6. Association between refugee status and linguistic outcomes, immigrants arriving after age 12.

\begin{tabular}{|c|c|c|c|c|c|c|c|c|c|c|}
\hline & AoA & AoA (drop words) & MSL & Accent & SPM & AoA & AoA(drop words) & MSL & Accent & SPM \\
\hline Refugee or mixed reasons & $\begin{array}{c}0.386^{* * *} \\
(0.098)\end{array}$ & $\begin{array}{c}0.352^{* * *} \\
(0.098)\end{array}$ & $\begin{array}{c}0.127 \\
(0.100)\end{array}$ & $\begin{array}{c}-0.00634 \\
(0.101)\end{array}$ & $\begin{array}{c}0.160 \\
(0.110)\end{array}$ & $\begin{array}{c}0.241^{* *} \\
(0.110)\end{array}$ & $\begin{array}{l}0.215^{*} \\
(0.112)\end{array}$ & $\begin{array}{l}0.0227 \\
(0.110)\end{array}$ & $\begin{array}{l}-0.134 \\
(0.121)\end{array}$ & $\begin{array}{l}0.0921 \\
(0.126)\end{array}$ \\
\hline Laborer & & & & & & $\begin{array}{l}-0.138 \\
(0.176)\end{array}$ & $\begin{array}{l}-0.149 \\
(0.178)\end{array}$ & $\begin{array}{l}-0.124 \\
(0.175)\end{array}$ & $\begin{array}{c}0.490^{* * *} \\
(0.189)\end{array}$ & $\begin{array}{c}0.00876 \\
(0.199)\end{array}$ \\
\hline Skilled & & & & & & $\begin{array}{l}0.0840 \\
(0.141)\end{array}$ & $\begin{array}{l}0.0763 \\
(0.142)\end{array}$ & $\begin{array}{l}0.0973 \\
(0.140)\end{array}$ & $\begin{array}{c}0.250 \\
(0.153)\end{array}$ & $\begin{array}{l}0.0398 \\
(0.161)\end{array}$ \\
\hline White Collar & & & & & & $\begin{array}{c}0.321^{* *} \\
(0.150)\end{array}$ & $\begin{array}{c}0.310^{* *} \\
(0.152)\end{array}$ & $\begin{array}{c}0.149 \\
(0.150)\end{array}$ & $\begin{array}{c}0.156 \\
(0.164)\end{array}$ & $\begin{array}{l}-0.137 \\
(0.173)\end{array}$ \\
\hline Urban & & & & & & $\begin{array}{l}0.175^{*} \\
(0.104)\end{array}$ & $\begin{array}{c}0.173^{*} \\
(0.105)\end{array}$ & $\begin{array}{r}-0.0446 \\
(0.103)\end{array}$ & $\begin{array}{c}-0.0444 \\
(0.113)\end{array}$ & $\begin{array}{l}0.0222 \\
(0.120)\end{array}$ \\
\hline Catholic & & & & & & $\begin{array}{l}-0.265 \\
(0.166)\end{array}$ & $\begin{array}{l}-0.272 \\
(0.167)\end{array}$ & $\begin{array}{c}-0.441^{* * *} \\
(0.165)\end{array}$ & $\begin{array}{r}-0.0983 \\
(0.175)\end{array}$ & $\begin{array}{c}-0.433^{* *} \\
(0.182)\end{array}$ \\
\hline Jewish & & & & & & $\begin{array}{l}0.0941 \\
(0.163)\end{array}$ & $\begin{array}{l}0.0525 \\
(0.165)\end{array}$ & $\begin{array}{r}-0.0847 \\
(0.162)\end{array}$ & $\begin{array}{c}0.220 \\
(0.174)\end{array}$ & $\begin{array}{l}-0.108 \\
(0.182)\end{array}$ \\
\hline Protestant & & & & & & $\begin{array}{l}-0.247 \\
(0.162)\end{array}$ & $\begin{array}{l}-0.252 \\
(0.164)\end{array}$ & $\begin{array}{c}-0.380^{* *} \\
(0.161)\end{array}$ & $\begin{array}{l}-0.108 \\
(0.172)\end{array}$ & $\begin{array}{c}-0.694^{* * *} \\
(0.182)\end{array}$ \\
\hline Orthodox & & & & & & $\begin{array}{c}-0.514^{* *} \\
(0.223) \\
\end{array}$ & $\begin{array}{c}-0.533^{* *} \\
(0.225) \\
\end{array}$ & $\begin{array}{c}-0.615^{* * *} \\
(0.221) \\
\end{array}$ & $\begin{array}{l}-0.337 \\
(0.242) \\
\end{array}$ & $\begin{array}{r}-0.0177 \\
(0.252) \\
\end{array}$ \\
\hline Outcome mean & -0.118 & -0.127 & -0.119 & -0.513 & -0.145 & -0.109 & -0.120 & -0.157 & -0.525 & -0.111 \\
\hline$R^{2}$ & 0.346 & 0.334 & 0.151 & 0.123 & 0.0941 & 0.384 & 0.369 & 0.197 & 0.162 & 0.170 \\
\hline$N$ & 454 & 454 & 454 & 393 & 383 & 360 & 360 & 360 & 317 & 309 \\
\hline
\end{tabular}

Note: This table reports the underlying coefficients for Figure 5 . Linguistic measures have been standardized. Refugee $=1$ indicates that an immigrant was coded as a refugee in both the first and second round of coding. Mixed reasons $=1$ indicates that an immigrant was coded as a refugee in only the first round or only the second round. Here, we combine the two into an indicator $=1$ if an immigrant was either coded as a refugee or as moving for mixed reasons. English speaking immigrants, those from Britain and Ireland, are not included in this sample. Controls for all regressions include age, age squared, arrival period, birthplace and gender. Results are unweighted.

$\mathrm{p}<0.1 ; * \mathrm{p}<0.05 ;{ }^{* * *} \mathrm{p}<0.01 ;$ standard errors are shown in parentheses. 
Appendix Table 7. Persecution related words in Age of Acquisition measure.

\begin{tabular}{|c|c|c|}
\hline Word & Age of Acquisition & Total Usage \\
\hline annexation & 13.85 & 1 \\
\hline anti & 9.37 & 170 \\
\hline armistice & 14 & 9 \\
\hline armistices & 14 & 1 \\
\hline army & 7.15 & 861 \\
\hline attack & 6.58 & 65 \\
\hline battalion & 11.95 & 29 \\
\hline bomb & 8 & 54 \\
\hline camps & 5.78 & 70 \\
\hline communism & 11.74 & 14 \\
\hline communist & 13.22 & 54 \\
\hline communists & 13.22 & 48 \\
\hline duty & 7.15 & 76 \\
\hline fascism & 14.33 & 3 \\
\hline fascist & 14.68 & 8 \\
\hline freedom & 7.05 & 175 \\
\hline genocide & 13.2 & 23 \\
\hline ghetto & 10.15 & 65 \\
\hline kill & 6.35 & 217 \\
\hline killed & 6.35 & 458 \\
\hline navy & 7.15 & 127 \\
\hline oven & 5.67 & 177 \\
\hline pogrom & 14.33 & 33 \\
\hline pogroms & 14.33 & 53 \\
\hline recession & 13.74 & 11 \\
\hline refugees & 10.56 & 107 \\
\hline revolution & 10 & 68 \\
\hline socialist & 13.61 & 25 \\
\hline socialists & 13.61 & 16 \\
\hline survive & 7.11 & 73 \\
\hline survived & 7.11 & 121 \\
\hline
\end{tabular}

Note: This table lists persecution related words used in oral histories. These words were dropped to create a robust Age of Acquisition measure, referred to as "Age of Acquisition (drop persecution words)" in main figures. 
Appendix Table 8. Regression of logarithm of income on self-reported English fluency from 1930-1940 matched data.

Outcome variable: $\ln ($ income $)$

\begin{tabular}{lcc}
\hline & $(1)$ & $(2)$ \\
\hline & No controls & Controls \\
\hline English fluency & $0.425^{* * *}$ & $0.161^{* * *}$ \\
& $(0.005)$ & $(0.005)$ \\
\hline mean ln(income) & 6.924 & 6.924 \\
$\mathrm{R}^{2}$ & 0.0114 & 0.0903 \\
$\mathrm{~N}$ & 739,566 & 739,566 \\
\hline
\end{tabular}

This table reports the coefficients obtained from two regressions using the 1930-1940 Census matched data: (1) $\ln$ (income) on selfreported English ability with no controls and (2) $\ln$ (income) on self-reported measure of English speaking ability with controls. English ability is a dummy variable that takes the value 1 if the individual reports speaking English. Controls include age, age squared, arrival period and birthplace. Sample consists of immigrants who arrived to the US after age 12. The sample only consists of immigrant men as women cannot be matched.

$\mathrm{p}<0.1 ;{ }^{* *} \mathrm{p}<0.05 ;{ }^{* * *} \mathrm{p}<0.01$; standard errors are shown in parentheses. 


\begin{tabular}{|c|c|c|c|c|c|c|c|c|c|c|}
\hline ID_base & row & first_name & middle_name & last_name & birthplace_general & birthplace_specific & birth_date & interviewer & interview_location & interview_year \\
\hline 1167 & 1 & Jenny & NA & Bohsung & Germany & Westhausen, Germany & NA & Margo Nash & NA & 1973 \\
\hline 1184 & 2 & John (Jack) & Brenden & Brady & Ireland & Ballyhaise, Ireland & $7 / 29 / 23$ & Paul E. Sigrest & $\begin{array}{l}\text { Ellis Island Recording } \\
\text { Studio }\end{array}$ & 1995 \\
\hline 1190 & 3 & Rose & NA & Breci & Italy & Carletini, Italy & NA & Dr. Willa Appel & $\begin{array}{l}\text { Ellis Island Recording } \\
\text { Studio }\end{array}$ & 1985 \\
\hline 1371 & 4 & Tilda & NA & De Mello & Brazil & Manaus, Brazil & $4 / 12 / 17$ & Janet Levine & Albertson, New York & 1992 \\
\hline 1494 & 5 & Rita & Costa & Finco & Italy & Asiago, Italy & $7 / 16 / 16$ & Janet Levine & Cudahy, Wisconsin & 1996 \\
\hline 1642 & 6 & Julia & Barlas & Groulx & Greece & NA & & Nancy Dallet & NA & 1989 \\
\hline
\end{tabular}

Appendix Figure 1. Image of standardized template used to manually extract data from oral histories. Image of part of template used by coders to fill in information for individuals in oral histories. 


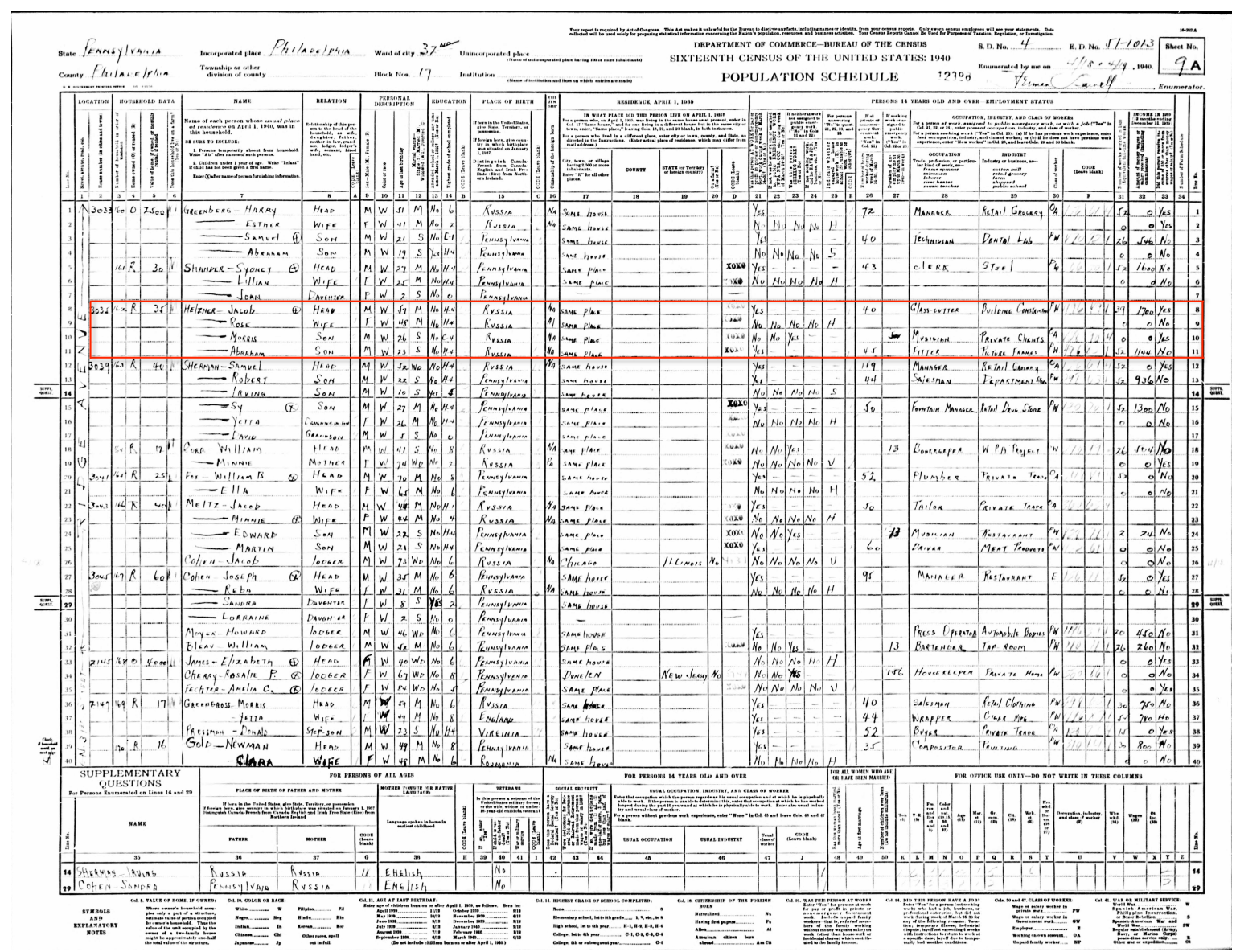

B

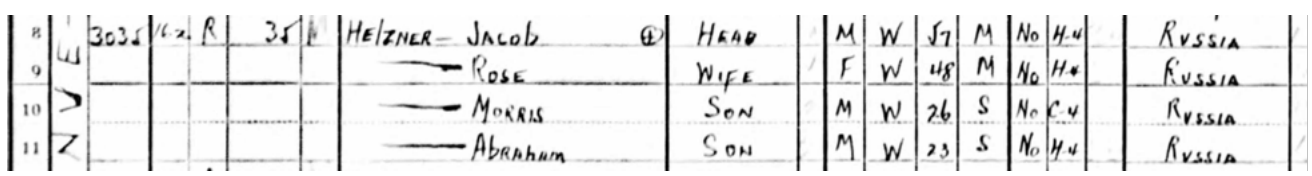

Appendix Figure 2. Example of a 1940 Census ledger page for Morris Helzner. A shows the full page of the 1940 census manuscript with Morris Helzner's family highlighted using the red rectangle. B zooms in on record for Morris Helzner on the page, one of the migrants that were linked to the 1940 census. Morris (row 10 in ledger) was the son of Jacob Helzner (household head on row 8). This household also had Morris' mother Rose (row 9) and brother Abraham (row 11). 


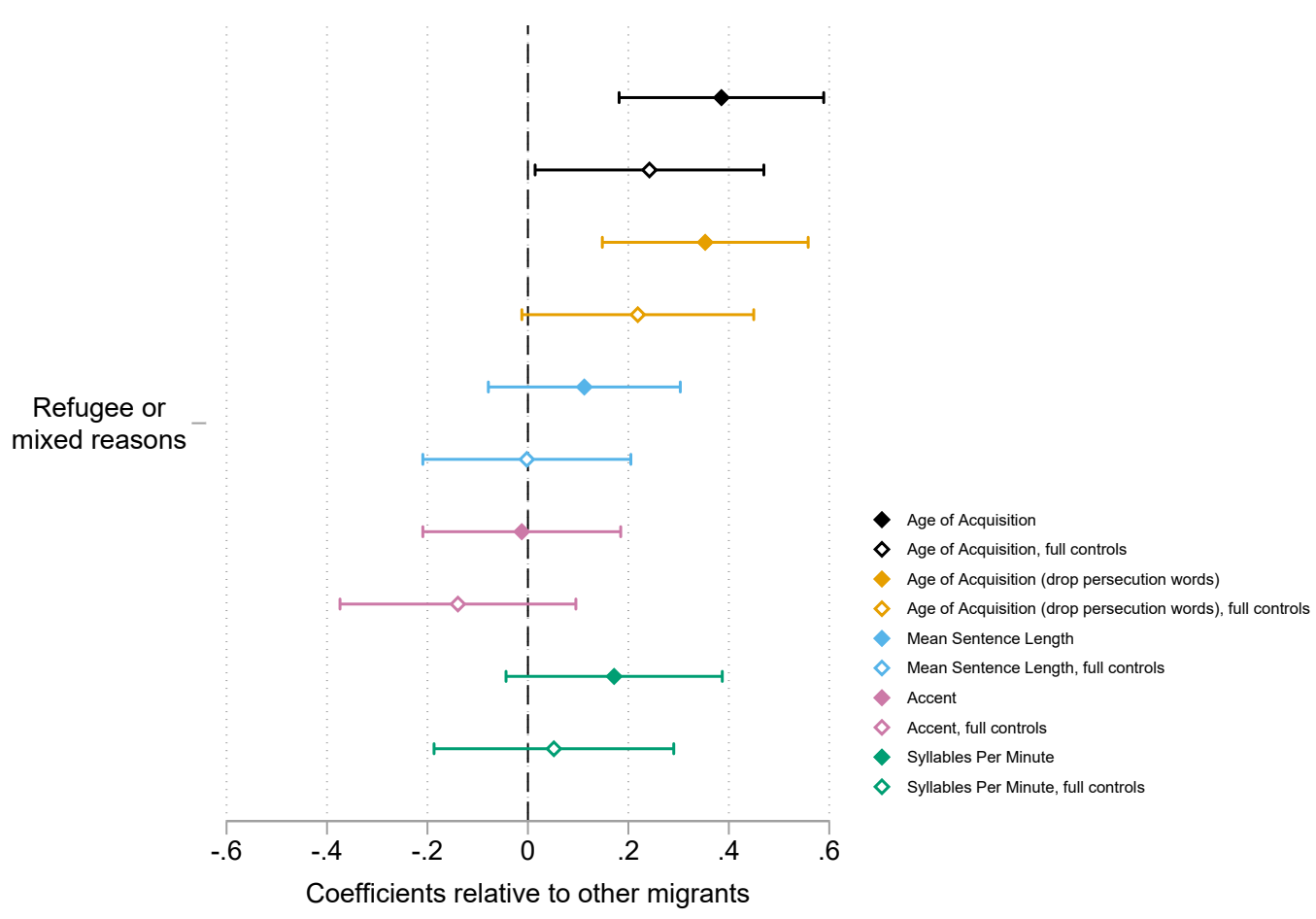

Appendix Figure 3. Association between refugee status and linguistic outcomes for immigrants arriving after age 12, English speakers included. Refugee $=1$ indicates that an immigrant was coded as a refugee in both the first and second round of coding. Mixed reasons $=1$ indicates that an immigrant was coded as a refugee in only the first round or only the second round. Here, we combine the two into an indicator $=1$ if an immigrant was either coded as a refugee or as moving for mixed reasons. English speaking immigrants, those from Britain and Ireland, are included in this sample. The five linguistic measures are: Age of Acquisition ( $\mathrm{N}=512, \mathrm{~N}=413$ with full controls), Age of Acquisition calculated after dropping persecution related words $(\mathrm{N}=512, \mathrm{~N}=413)$, Mean Sentence Length $(\mathrm{N}=512, \mathrm{~N}=413)$, Accent $(\mathrm{N}=449, \mathrm{~N}=368)$ and Syllables Per Minute $(\mathrm{N}=438, \mathrm{~N}=359)$. Linguistic measures have been standardized to have a mean of zero and standard deviation of one. A more positive accent score indicates an accent closer to that of the US born. Controls for all regressions include age, age squared, arrival period, birthplace and gender. Added controls in regressions with "full controls" include father's pre-migration occupation, pre-migration urban status and religion. Significance is at the $5 \%$ level. 


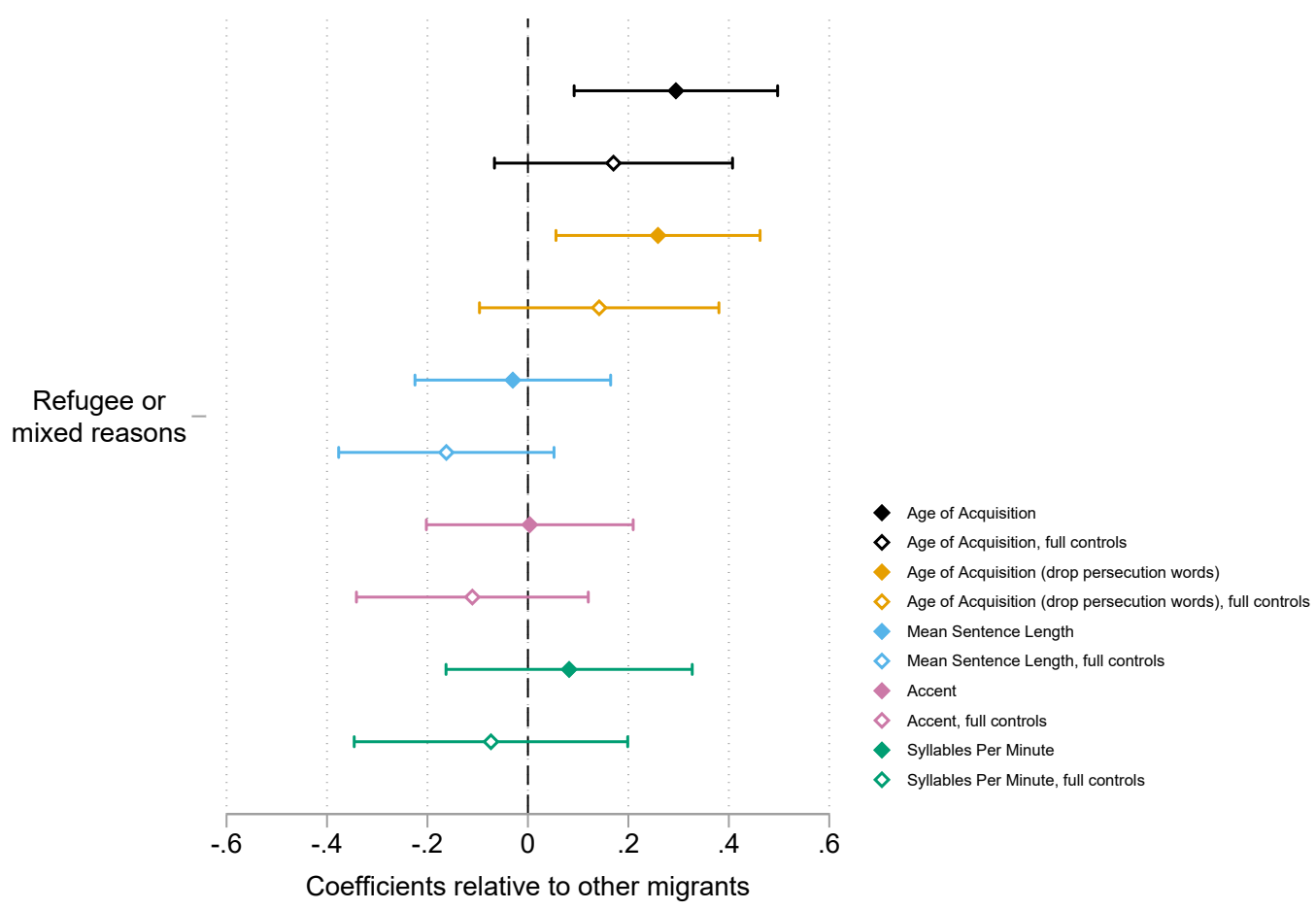

Appendix Figure 4. Association between refugee status and linguistic outcomes for immigrants arriving after age 12, dropping migrants arriving after 1933, English speakers included. Refugee $=1$ indicates that an immigrant was coded as a refugee in both the first and second round of coding. Mixed reasons $=1$ indicates that an immigrant was coded as a refugee in only the first round or only the second round. Here, we combine the two into an indicator $=1$ if an immigrant was either coded as a refugee or as moving for mixed reasons. English speaking immigrants, those from Britain and Ireland, are included in this sample. The four linguistic measures are: Age of Acquisition $(\mathrm{N}=424, \mathrm{~N}=340$ with full controls), Age of Acquisition calculated after dropping persecution related words $(\mathrm{N}=424, \mathrm{~N}=340)$, Mean Sentence Length $(\mathrm{N}=424, \mathrm{~N}=340)$, Accent $(\mathrm{N}=372, \mathrm{~N}=302)$ and Syllables Per Minute $(\mathrm{N}=362, \mathrm{~N}=294)$. Linguistic measures have been standardized to have a mean of zero and standard deviation of one. Controls for all regressions include age, age squared, arrival period, birthplace and gender. Added controls in regressions with "full controls" include father's pre-migration occupation, pre-migration urban status and religion. Controls for all regressions include age, age squared, arrival period, birthplace and gender. Added controls in regressions with "full controls" include father's pre-migration occupation, pre-migration urban status and religion. Results are unweighted. Significance is at the $5 \%$ level. 


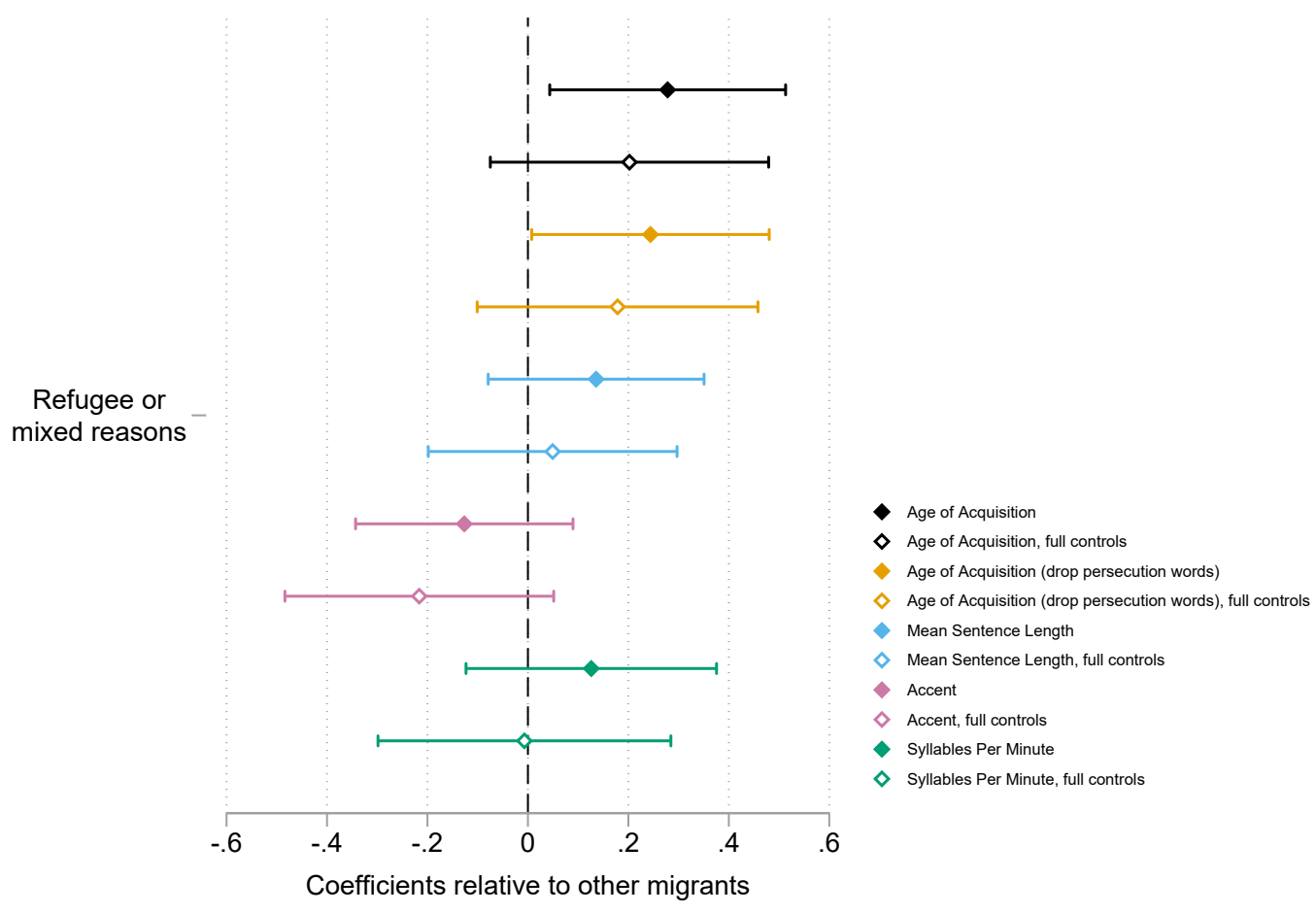

Appendix Figure 5. Association between refugee status and linguistic outcomes for immigrants arriving after age 14, English speakers included. Refugee $=1$ indicates that an immigrant was coded as a refugee in both the first and second round of coding. Mixed reasons $=1$ indicates that an immigrant was coded as a refugee in only the first round or only the second round. Here, we combine the two into an indicator $=1$ if an immigrant was either coded as a refugee or as moving for mixed reasons. English speaking immigrants, those from Britain and Ireland, are included in this sample. The five linguistic measures are: Age of Acquisition ( $\mathrm{N}=415, \mathrm{~N}=331$ with full controls), Age of Acquisition calculated after dropping persecution related words $(\mathrm{N}=415, \mathrm{~N}=331)$, Mean Sentence Length $(\mathrm{N}=415, \mathrm{~N}=331)$, Accent $(\mathrm{N}=363, \mathrm{~N}=296)$ and Syllables Per Minute $(\mathrm{N}=355, \mathrm{~N}=288)$. Linguistic measures have been standardized to have a mean of zero and standard deviation of one. Controls for all regressions include age, age squared, arrival period, birthplace and gender. Added controls in regressions with "full controls" include father's pre-migration occupation, pre-migration urban status and religion. Significance is at the 5\% level. 


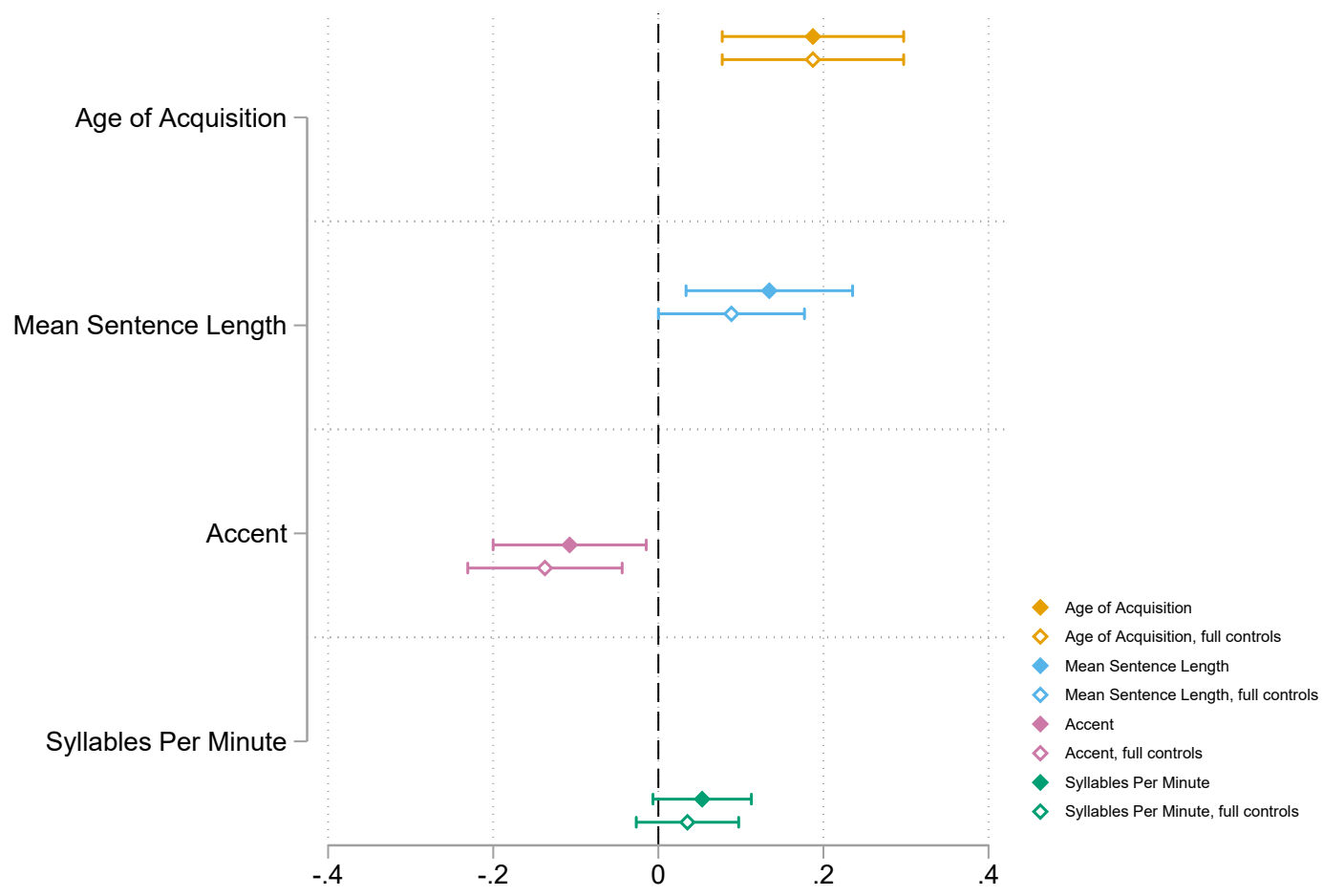

Appendix Figure 6. Regressions of logarithm of income score on linguistic measures, English speakers included. This figure documents the results of four regression models: logarithm of income score on (i) Age of Acquisition ( $N=341$, $N=267$ with full controls), (ii) Mean Sentence Length $(N=341, N=267)$, (iii) Accent $(N=304, N=240)$ and (iv) Syllables Per Minute $(N=294, N=231)$. Linguistic measures have been standardized. Controls include age, age squared, arrival period, birthplace, gender and an indicator for arriving before or after the age of 12. Added controls in regressions with "full controls" include father's pre-migration occupation, pre-migration urban status and religion. Results are weighted by the propensity of being matched. English speaking immigrants, those from Britain and Ireland, are included in this sample. Significance is at the $5 \%$ level. 